\title{
Flood-risk mapping: contributions towards an enhanced assessment of extreme events and associated risks
}

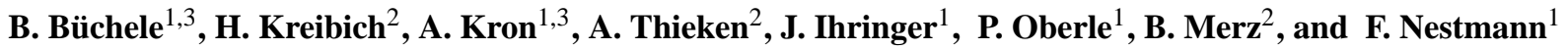 \\ ${ }^{1}$ Institute for Water and River Basin Management, Technical University of Karlsruhe, Germany \\ ${ }^{2}$ GeoForschungsZentrum Potsdam, Section Engineering Hydrology, Potsdam, Germany \\ ${ }^{3}$ Center for Disaster Management and Risk Reduction Technology (CEDIM), Karlsruhe, Germany
}

Received: 5 January 2006 - Revised: 22 March 2006 - Accepted: 28 March 2006 - Published: 12 June 2006

\begin{abstract}
Currently, a shift from classical flood protection as engineering task towards integrated flood risk management concepts can be observed. In this context, a more consequent consideration of extreme events which exceed the design event of flood protection structures and failure scenarios such as dike breaches have to be investigated. Therefore, this study aims to enhance existing methods for hazard and risk assessment for extreme events and is divided into three parts. In the first part, a regionalization approach for flood peak discharges was further developed and substantiated, especially regarding recurrence intervals of 200 to 10000 years and a large number of small ungauged catchments. Model comparisons show that more confidence in such flood estimates for ungauged areas and very long recurrence intervals may be given as implied by statistical analysis alone. The hydraulic simulation in the second part is oriented towards hazard mapping and risk analyses covering the whole spectrum of relevant flood events. As the hydrodynamic simulation is directly coupled with a GIS, the results can be easily processed as local inundation depths for spatial risk analyses. For this, a new GIS-based software tool was developed, being presented in the third part, which enables estimations of the direct flood damage to single buildings or areas based on different established stage-damage functions. Furthermore, a new multifactorial approach for damage estimation is presented, aiming at the improvement of damage estimation on local scale by considering factors like building quality, contamination and precautionary measures. The methods and results from this study form the base for comprehensive risk analyses and flood management strategies.
\end{abstract}

Correspondence to: $\mathrm{B}$. Büchele

(buechele@iwg.uka.de)

\section{Introduction}

Within the framework of the Center for Disaster Management and Risk Reduction Technology (CEDIM, a cooperation between the University of Karlsruhe and the GFZ Potsdam), the project "Risk Map Germany" aims to provide improved methods and data for the quantification and mapping of risks. Here, in particular the developments concerning flood risk assessment are presented. The damages in Germany due to severe flood disasters in the last decades amount to billions of Euro. Examples are the Rhine floods in 1993 with $530 \mathrm{M}$, and in 1995 with $280 \mathrm{M}$, the Odra flood in 1997 with $330 \mathrm{M}$, the Danube flood in 1999 with $412 \mathrm{M}$, the Elbe and Danube flood in 2002 with $11800 \mathrm{M}$ (Kron, 2004). The need of specific research efforts and spatial data, particularly hazard or risk maps, for an improved risk assessment and prevention on regional and local level is evident.

In this project, "hazard" is defined as the occurrence of a flood event with a defined exceedance probability. "Risk" is defined as the potential damages associated with such an event, expressed as monetary losses. It becomes clear that hazard and risk quantification depend on spatial specifications (e.g., area of interest, spatial resolution of data). With regard to flood risk, the local water level is decisive for the occurrence of damage (e.g. Smith, 1994; see below). Therefore, a high level of detail, i.e. an appropriate scale of flood maps is a fundamental precondition for a reliable flood risk assessment. Detailed spatial information on flood hazard and vulnerability is necessary for the development of regional flood-management concepts, planning and cost-benefit analysis of flood-protection measures and, extremely important, for the preparedness and prevention strategies of individual stakeholders (communities, companies, house owners etc.). Moreover, the mapped information that an area or object is potentially endangered due to a given flood scenario directly implies legal and economical consequences such as competencies of public authorities for flood control and spatial planning, owner interests, insurance polices, etc.

Published by Copernicus GmbH on behalf of the European Geosciences Union. 
In Germany, the federal states (Bundesländer) are responsible for flood management and for the generation of flood maps. Many state authorities have been working for years on the delineation of inundation zones with map scales of up to $\geq 1: 5000$ in urban areas in order to recognise the flood hazard for discrete land-parcels and objects. Increasingly, public flood-hazard maps are available on internet platforms (e.g., Nordrhein-Westfalen, 2003, Rheinland-Pfalz, 2004, Sachsen, 2004, Bayern, 2005, Baden-Württemberg, 2005). In the next years, with respect to amendments in legislation, regional significance and technical possibilities, flood-hazard maps with high spatial resolutions can be expected successively for all rivers in Germany. Details of procedures and mapping techniques vary from state to state and due to local concerns (e.g., data availability, vulnerability, public funds). An overview of different approaches is published by Kleeberg (2005). For example in Baden-Württemberg, two types of flood-hazard maps will be provided for all rivers with catchment areas $>10 \mathrm{~km}^{2}$. The first map will show the extent of inundation zones of the 10-, 50- and 100-year event, supplemented by an "extreme event" being in the order of magnitude of a 1000-year event and, as documented, information on historical events. The second map will provide the water depths of the 100 -year event. The basic requirements and typical features of these upcoming nation-wide mosaic of flood-hazard maps can be drafted as follows (compare e.g. UM Baden-Württemberg, 2005, MUNLV, 2003):

- Representation of present flood-relevant conditions (updating after significant changes)

- Representation of inundation zones for flood events of different recurrence intervals up to generally 100 years, for large rivers 200 years (e.g., Rhine)

- Representation of inundation depths, potentially flow velocities

- Representation of extreme, historical events (exceeding the 100-year event, as available)

- Representation of flood-protection measures, potentially local hazard sources

- Level of detail for local analyses and planning purposes

Following these requirements on flood-hazard assessment and related purposes on local scale, one can rely on a set of methods for the quantification of hydrological and hydraulic parameters and their spatial intersection with digital terrain models (DTM) and land-use data. A number of investigations (e.g. Uhrich et al., 2002) showed that the quality of flood maps strongly depends on the quality of the DTM used. Uncertainties in DTMs are more and more overcome by an increasing availability of high-resolution digital terrain models from airborne surveys (e.g., Laserscanner or aerial photographs). In spite of these technical standards and advances in practice, it can be noted that flood-risk assessment remains a quite challenging task, especially regarding the uncertainties related to extreme events exceeding the design flood or to the damage due to failures of flood control measures (Apel et al., 2004; Merz et al., 2004). For example, uncertainties associated with flood frequency analyses are discussed by Merz and Thieken (2005). However, the visualisation and communication of uncertain information in hazard maps should be optimised in a way, that non-experts can understand, trust and get motivated to respond to uncertain knowledge (Kämpf et al., 2005).

In contrast to hazard mapping, the assessment of damage and its visualisation as risk maps is still far from being commonly practised in Germany. Risk maps, however, help stakeholders to prioritise investments and they enable authorities and people to prepare for disasters (e.g., Takeuchi, 2001; Merz and Thieken, 2004). Good examples for risk assessments and maps are - among others - the ICPR RhineAtlas (ICPR, 2001), the programme of flood-hazard mapping in Baden-Württemberg (UM Baden-Württemberg, 2005), the integrated flood management conception in the Neckar river basin (IkoNE, 2002), the DFNK approach for the city of Cologne (Apel et al., 2004; Grünthal et al., 2006), and the risk assessment in England and Wales (Hall et al., 2003). Since flood risk encompasses the flood hazard and the consequences of flooding (Mileti, 1999), such analyses require an estimation of flood impacts, which is normally restricted to detrimental effects, i.e. flood losses. In contrast to the above discussed hydrological and hydraulic investigations, flood damage modelling is a field which has not received much research attention and the theoretical foundations of damage models need to be further improved (Wind et al., 1999; Thieken et al., 2005).

A central idea in flood damage estimation is the concept of damage functions. Most functions have in common that the direct monetary damage is related to the inundation depth and the type or use of the building (e.g. Smith, 1981; Krzysztofowicz and Davis, 1983; Wind et al., 1999; NRC, 2000; Green, 2003). This concept is supported by the observation of Grigg and Helweg (1975) "that houses of one type had similar depth-damage curves regardless of actual value". Such depth-damage functions, also well-known as stage-damage-functions, are seen as the essential building blocks upon which flood damage assessments are based and they are internationally accepted as the standard approach to assess urban flood damage (Smith, 1994).

Probably the most comprehensive approach has been the Blue Manual of Penning-Rowsell and Chatterton (1977) which contains stage-damage curves for both residential and commercial property in the UK. In Germany, most stagedamage curves are based on the most comprehensive German flood damage data base HOWAS that was arranged by the Working Committee of the German Federal States' Water Resources Administration (LAWA) (Buck and Merkel 1999; Merz et al., 2004). But recent studies have shown 
that stage-damage functions may have a large uncertainty (e.g. Merz et al., 2004).

The investigation concept within the CEDIM working group "flood risk" is based on the main goal to improve the flood-risk assessment on local scale in different modules of the quantification procedure. Special attention is given to extreme events. This was realised in pilot areas in BadenWürttemberg, where a good data and model basis is given.

Following this modular concept, the quantification procedure can be divided in three major steps:

- Regional estimation of flood discharges (basin-, sitespecific hydrological loads)

- Estimation of flow characteristics in potential inundation areas (local hydraulic impacts)

- Estimation of the resulting damages (area- or objectspecific risk assessment)

An overview of suitable approaches for these steps of hazard and vulnerability assessments is given in Table 1 . The left column states minimum requirements on data and methods for a standard quality of hazard and risk assessment on local scale in Germany. The right column lists more sophisticated approaches which require more spatial information and more complex calculations up to fully dynamic simulations of unobserved extreme flood situations. Parts highlighted in bold letters are further addressed by the present study, without giving priority to any of the listed possibilities. The present paper is structured in the Sects. 2, 3 and 4 according to the above mentioned steps, respectively.

\section{Estimation of extreme flood events and their proba- bilities}

\subsection{Basis and objectives}

The estimation of flood frequencies is well-known as a key task in flood hazard assessment. Actually, the availability of reliable and spatially distributed event parameters for extreme floods is a fundamental prerequisite for any comprehensive flood-risk management. For instance, peak discharges for recurrence intervals up to $\mathrm{T}=100$ years (corresponding to an exceedance probability of one percent per year) are commonly accounted in flood mapping and floodprotection planning. Peak discharges for larger events with recurrence intervals up to 1000 or even 10000 years are required for dam safety analyses (cf. DIN 19700), hazard mapping for extreme cases, related risk analyses and emergency planning purposes. For example in Baden-Württemberg, a guideline gives specific technical recommendations for the dimensioning of flood-protection measures (LfU, 2005a). These recommendations already include the preventative consideration of potential impacts of future climate change on peak discharges by a so-called "climate change factor" proposed by Ihringer (2004) based on statistical analyses of downscaled regional climate-model outputs.

On the other hand, it is important to bear in mind that flood-estimation procedures in practice mainly rely on observed discharge data. In the field of hydrology, it has long been recognised that many annual maximum flood series are too short to allow a reliable estimation of extreme events, leading to the conclusion that instead of developing new methodologies for flood-frequency analysis, the comparison of existing methods and the search for other sources of information have to be intensified (e.g., Bobée et al., 1993). This is especially true for small catchment areas where the availability of flow data is generally worse (numerous ungauged areas or rather short periods of records). According to this, the need of regional analyses to compensate the lack of temporal data and to introduce a spatial dimension in flood estimates is evident. Beside flood-frequency analysis, regional analyses can help to identify physical or meteorological catchment characteristics that cause similarity in flood response. Considerable uncertainties, although being an intrinsic part of extreme value estimations, can be managed by the complementary use of different methods (e.g., flood-frequency analysis and rainfall-runoff models). In fact, a stepwise approximation from different directions, involving both statistical theory as well as knowledge of catchment characteristics and flood processes seems to be the most viable way to build confidence in flood estimates, to identify and exclude implausible values and thus, to reduce uncertainties to a smaller bandwidth.

Hence, the specific goal here is to discuss a regionalization method for state-wide flood probabilities in BadenWürttemberg. Emphasis is given to comparisons among models for recurrence intervals from 200 to 10000 years.

\subsection{Method and data}

The first regionalization methods for flood estimates in Baden-Württemberg were developed in the 1980's (Lutz, 1984). In 1999, the following regionalization approach for the mean annual peak discharge $(M H Q)$ and peak discharges $\left(H Q_{T}\right)$ for recurrence intervals $T$ from 2 to 100 years, partially 200 years was published (LfU, 1999), followed by an updated version on CD in 2001 (LfU, 2001). The approach is based on flood frequency analyses at 335 gauges which cover catchment areas from less than $10 \mathrm{~km}^{2}$ $\left(\sim 7 \%\right.$ of all gauges) to more than $1000 \mathrm{~km}^{2}(\sim 7 \%)$ and periods of records varying from a minimum of 10 to more than 100 years (average 45 years). At large, these statistical analyses at single gauges involved 12 types of theoretical cumulative distribution functions (cdfs); the parameter estimation was done using the method of moments and the method of maximum likelihood. The final selection of cdfs was supported by regional comparisons (e.g., for neighboured gauges) to avoid inconsistencies especially for higher recurrence intervals. 
Table 1. Overview of methods and data for high-resolution flood-risk mapping in Germany. The left column (basic approaches) indicates minimum requirements on data and analysis expenses, the right column stands for more detailed approaches (additional requirements, only in particular cases needed/possible). Parts in bold letters are addressed in this article.

\begin{tabular}{ll}
\hline $\begin{array}{l}\text { Basic approach } \\
\text { (minimum requirements) }\end{array}$ & $\begin{array}{l}\text { More detailed approach (higher spatial } \\
\text { differentiation, inclusion of dynamic } \\
\text { aspects) }\end{array}$
\end{tabular}

Regional estimation of flood discharges draulic impacts

- Documentation of historical water levels/inundation zones (varying availability/quality)

- Calculation of water levels and inundation zones/depths based on hydraulic models and digital terrain models (local scale, e.g. 1:5000)

- Simplified approaches (only large-scale, e.g. 1:50 000)

Damage estimation

- stage-damage curves for aggregated spatial data (e.g., ATKISdata)
- Rainfall-runoff simulation for extreme flood events

- Long-term simulation of flood variability (probabilistic evaluation, e.g. climate trends)

- assessment of flow situation based on 2-D HN models (e.g., spatial distribution of flow velocities/directions)

- unsteady hydrodynamic simulation of extreme flood scenarios (e.g., impact of dike failures)
Beside the gauge-specific flood quantiles, the following eight parameters as spatial data sets for approximately 3400 catchment areas are taken into account by the regionalization approach.

$\begin{array}{ll}A_{E 0} & \text { catchment area }\left[\mathrm{km}^{2}\right] \\ S & \text { percentage of urban area [\%] } \\ W & \text { percentage of forest area [\%] } \\ I_{g} & \text { weighted slope [\%] } \\ L & \begin{array}{l}\text { length of flow path from head of catchment } \\ \text { to mouth [km] }\end{array} \\ L_{C} & \begin{array}{l}\text { length of flow path from center of catchment } \\ \text { to mouth [km] }\end{array} \\ h_{N G} & \text { mean annual precipitation depth [mm] } \\ L F & \text { landscape factor [-] }\end{array}$

These eight parameters, especially $h_{N G}$ and $L F$, were identified as significant for the peak discharge. $L F$ is an empirical factor and represents all kind of regional influences, particularly geological characteristics. Together, they are taken into account in the following multiple linear regression equation, which is used asapproach for flood quantile estimation (i.e. $M H Q$ and $H Q_{T}$ ) especially for ungauged sites:

$$
\begin{aligned}
& \ln (Y)=C_{0}+C_{1} \times \ln \left(A_{E_{0}}\right)+C_{2} \times \ln (S+1) \\
& +C_{3} \times \ln (W+1)+C_{4} \times \ln \left(I_{g}\right)+C_{5} \times \ln (L) \\
& +C_{6} \times \ln \left(L_{C}\right)+C_{7} \times \ln \left(h N_{G}\right)+C_{8} \times \ln (L F)
\end{aligned}
$$




$\begin{array}{cl}\text { with: } & \\ Y, Y_{T} & \text { dependant variable: } \\ & Y=M H q \text { for regionalization of } M H Q \\ & Y_{T}=\mathrm{Hq}_{T} / M H q \text { for regionalization of } H Q_{T} \\ M H q & \text { mean annual peak discharge per unit area } \\ & {\left[\mathrm{m}^{3} /\left(\mathrm{s} \times \mathrm{km}^{2}\right)\right]} \\ H q_{T} & \text { annual peak discharge per unit area } \\ & {\left[\mathrm{m}^{3} /\left(\mathrm{s} \times \mathrm{km}^{2}\right)\right] \text { of recurrence interval } T} \\ C_{0} \ldots C_{8} & \text { regression coefficients }\end{array}$

The regression coefficients $C_{0} \ldots C_{8}$ are estimated based on the gauge-specific flood estimates and the above mentioned spatial data sets (available in LfU, 2005b) using the method of least squares. The application of this approach requires two steps. First, $M H q$ is estimated using Eq. (1). Subsequently, $H Q_{T}$ in unit $\left[\mathrm{m}^{3} / \mathrm{s}\right]$ is determined using $Y_{T}=H q_{T} / M H q$ in Eqs. (1) and (2):

$$
H Q_{T}=Y_{T} \times M H q \times A_{E_{0}}=Y_{T} \times M H Q
$$

Recently, this approach was extended to recurrence intervals of 200 to 10000 years using a selection of 249 gauges and applied to a more detailed spatial data set (6200 locations of the river network, LfU 2005b). The selection of gauges was done considering the record length and the quality of the flow series in order to achieve more reliable model adjustments for low-frequency events. The present regionalization approach is thus consisting of 13 regression equations, i.e. one equation for $M H Q$ and each $H Q_{T}$ for $T$ from 2 to 10000 years. The coefficients $\left(C_{0}-C_{8}\right)$ of these equations are fully documented in LfU (2005b), at which the corresponding coefficients of determination are $R^{2}>0.99$ for all single recurrence intervals (logarithmic analysis). As Fig. 1 exemplifies for $C_{7}$ and $C_{8}$ (compare Eq. 1), the coefficients show a homogeneous progression upon the whole spectrum of recurrence intervals, although they are estimated separately for each recurrence interval. To enable user-specific estimates, the complete spatial data sets and a calculation tool for the regionalization approach are integrated in a geographical information system (LfU, 2005b), which is distributed as stand-alone software to local authorities and planning companies. By these means, regionalized $M H Q$ and $H Q_{T}$ are provided for any user-defined location of the river network in Baden-Württemberg, completed by analogous information at 375 gauges and longitudinal profiles for 163 major rivers. Furthermore, the extension of the regionalization approach to very high recurrence intervals supports the ongoing state-wide elaboration of flood hazard maps and regional dam safety analyses.

\subsection{Model results, comparisons and discussion}

A comparison of at-site and regional flood-frequency analysis is exemplified in Fig. 2 for the Fils river in Plochingen showing that the regionalized $H Q_{T}$ (squares) are very similar to the statistical distribution for the annual maximum flood series 1926-2002 (solid line). Beyond the agreement

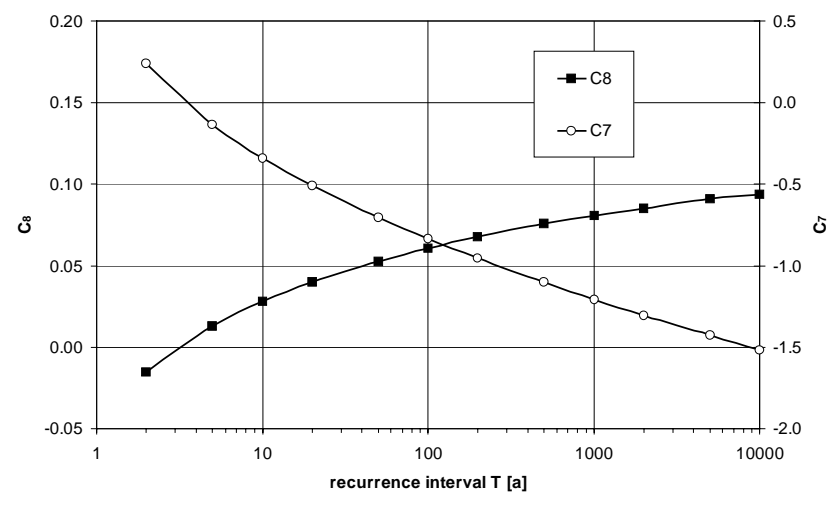

Fig. 1. Progression of regression coefficients $C_{7}$ and $C_{8}$ for recurrence intervals $T$ from 2 to 10000 years.

for this specific gauge it may be noticed that the regionalization approach is able to reproduce the shape of the statistical distribution. At the same time, the 95\%-confidence interval for the statistical distribution (dashed lines) is indicating substantial uncertainties, especially in the area of extrapolation (for this sample: about $25 \%$ for all $H Q_{T}$ with $\mathrm{T} \geq 100$ years). Summing up, the deviations between regionalization and flood-frequency analysis vary among the mentioned 249 gauges as presented in Fig. 3. The mean deviation is $<2.5 \%$ at approx. $40 \%$ of the gauges, $<7.5 \%$ at approx. $75 \%$ and $<12.5 \%$ at approx. $90 \%$. The deviation is $>20 \%$ at approx. $3 \%$ of the gauges where generally human activities (e.g., urban drainage systems) or karst conditions are present. Figure 4 illustrates a sample map of the regionalization approach for $H q_{1000}$ in Baden-Württemberg. According to this sample, the highest peak discharges per unit area occur in the mountainous regions of the Black Forest (Upper Rhine Basin) and the upper Neckar Basin.

To substantiate the regionalization approach especially for small ungauged catchment areas, the results can be compared to outcomes of rainfall-runoff (RR) models which are supposed to build on a better representation of catchment characteristics. This was done here for the Fils catchment, a tributary to the Neckar River $\left(707 \mathrm{~km}^{2}\right.$, see Fig. 4), where a RR-model (software see Ihringer, 1999) is available from a hydrological study on local flood problems. Within the RR-model, the catchment is represented by 907 subareas and 1501 nodes for the drainage network, considering a total urban area of $92 \mathrm{~km}^{2}, 331$ stormwater holding tanks of urban drainage systems and 7 flood-retention basins. As input of the RR-model, rainfall statistics provided by the German Weather Service (DWD, 1997) were used; these rainfall statistics cover recurrence intervals from 1 to 100 years for different duration classes from 0.5 to $72 \mathrm{~h}$. For the assessment of higher peak discharges, the mean precipitation depths for the different duration classes were extrapolated. However, different precipitation characteristics (duration classes) cause a set of different flood peaks. Therefore, 


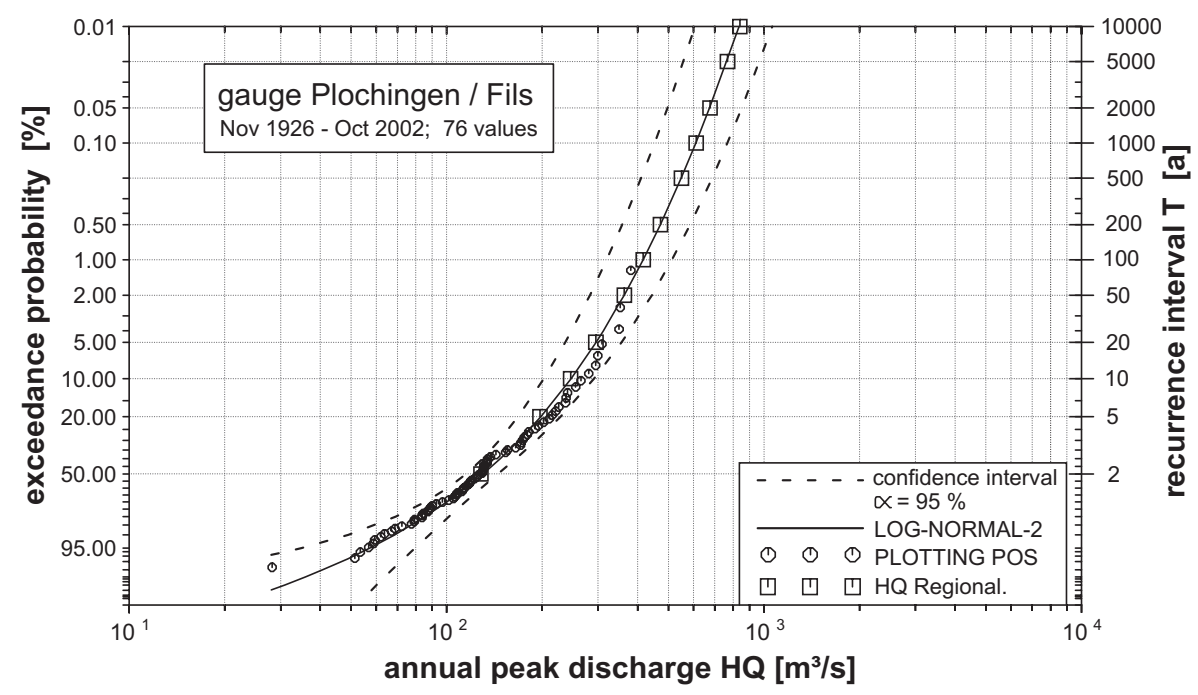

Fig. 2. Comparison of $H Q_{T}$ from regionalization (as squares) with flood-frequency analysis at Plochingen/Fils (location see Fig. 4, annual peak discharges 1926-2002 as plotting positions, Log-Normal distribution as solid line, 95\%-confidence interval as dashed lines).

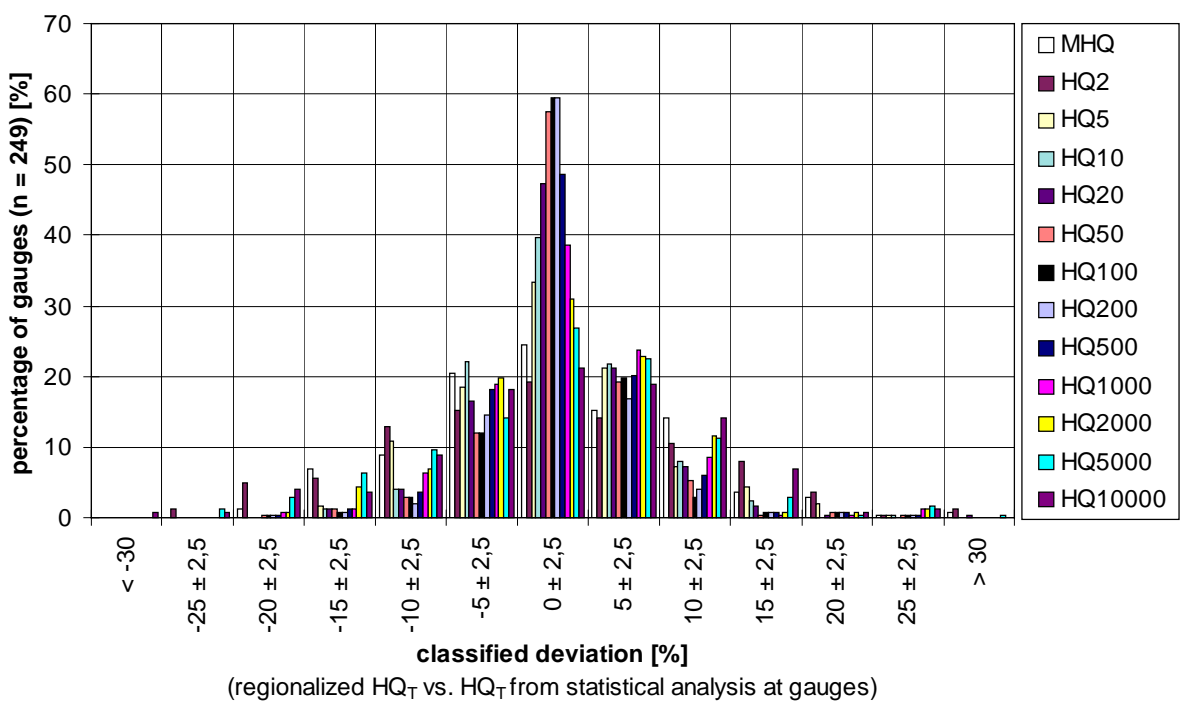

Fig. 3. Comparison between regionalization and flood-frequency analysis at 249 gauges in Baden-Württemberg: classified deviations [\%] for $M H Q$ and $H Q_{T}$ for $T=2, \ldots, 10000$ a (bars from left to right).

the maximum peak of a set representing the relevant spectrum of precipitation characteristics was chosen to estimate the 1000-year quantile according of this approach. This value is compared to the quantile estimated from the regionalization approach based on observed flood peaks. Figure 5 shows a comparison of 1000-year peak discharges of both models ( $H Q_{1000}$ from regionalization and $\left.\mathrm{RR}\right)$. According to the spatial discretization of the regionalization approach, 265 locations of the drainage network are plotted. The axes are logarithmic in order to visualise the small values better. It can be concluded that the results match fairly well with tendencies to higher deviations between both approaches in smaller ar- eas (especially for $H Q_{1000}<10 \mathrm{~m}^{3} / \mathrm{s}$ ). The variation around the bisecting line, standing for a perfect agreement of both models, can be understood as residual uncertainty of the mutual application of both models for these specific catchment areas. The deviations may be further discussed taking more knowledge on local characteristics into account, that was not yet used in one or both models (e.g., outlets of urban drainage systems). Mathematically, the deviations between both models amount to $<7.5 \%$ for $66 \%$ of all 265 plotted locations, $<12.5 \%$ for $82 \%$ and $>30 \%$ for $3 \%$ of these locations. The latter belong to smaller areas respectively peak discharges (e.g., $6.96 \mathrm{~m}^{3} / \mathrm{s}$ from regionalization versus $11.02 \mathrm{~m}^{3} / \mathrm{s}$ from 

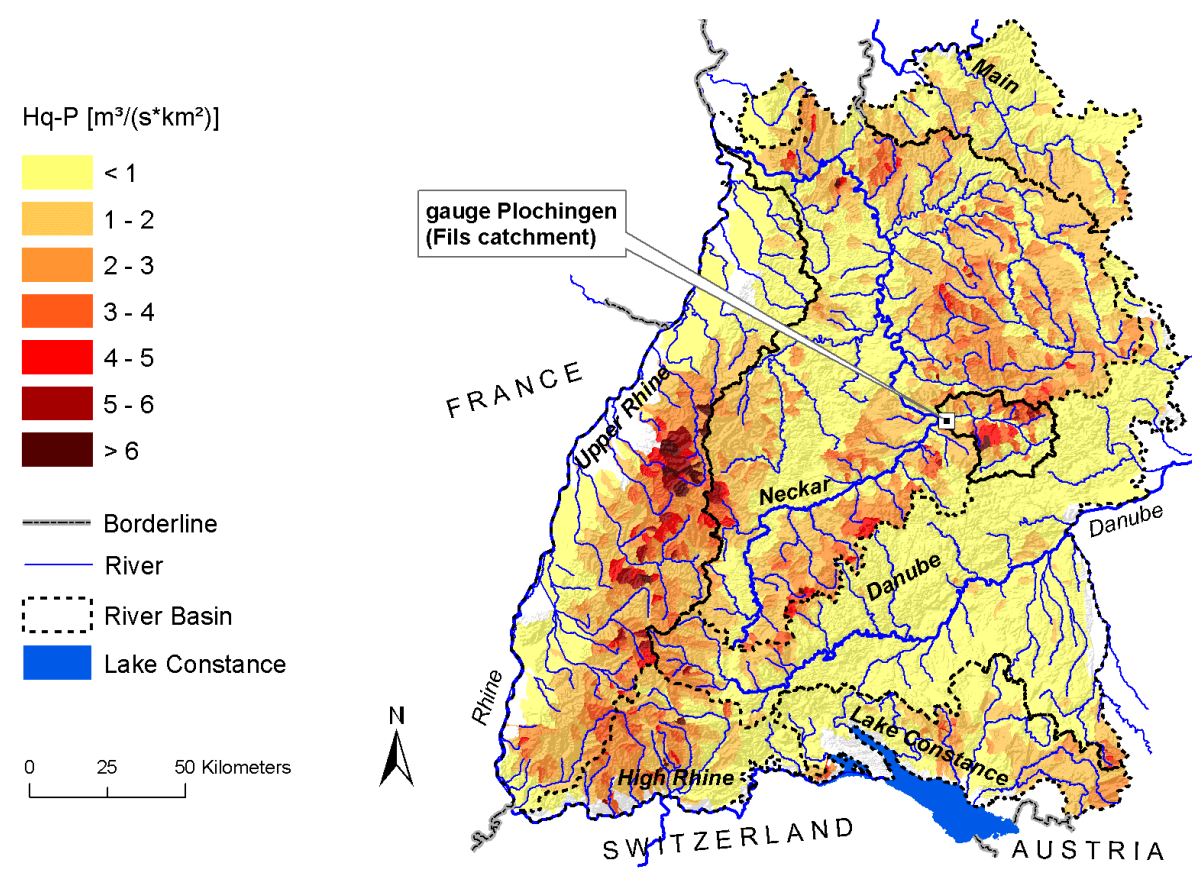

Fig. 4. Regionalized $H q_{1000}$ in Baden-Württemberg; location of sample gauge in Plochingen (Fils catchment, $704 \mathrm{~km}^{2}$ ).

RR, Fig. 5) where the RR-model - in general - may recognise local influences better. Therefore, more confidence may be given to the regionalized $H Q_{T}$ as implied by statistical analysis alone (Fig. 2).

In view of the needs of practitioners, a coherent and robust approach for regional flood estimates is thus available and broadly established in a state-wide sense. Uncertainties of this approach concerning local distinctions call for hydrological justifications of the plausibility of flood estimates on local scale. The model comparison strategy seems to be the logical way for model validation and practically the unique chance to reduce uncertainties effectively in areas where the availability of flow records is scarce. This is valid not only in spatial sense (ungauged areas) but also for the extrapolation to very long recurrence intervals. Apart from its practical use for regional flood estimates, the regionalization approach leads from at-site flood frequency analysis to distributed hydrologic modelling of flood events, enabling a vice-versa review and mutual enhancement of these methods.

\section{Hydrodynamic modelling for extreme floods}

\subsection{Basis and objectives}

To quantify flood hazard and risk in urban areas or at individual locations, flood discharges (e.g., $H Q_{100}$ ) have to be transformed into hydraulic parameters like water levels, inundation depths or flow velocities by means of hydrodynamic-numerical (HN) models. In many cases when

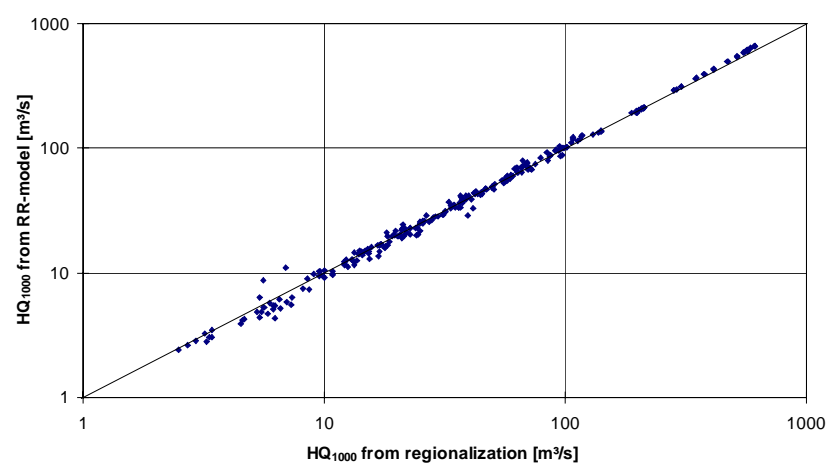

Fig. 5. Comparison of peak discharges calculated by regionalization and RR-model: $H Q_{1000}$ at 265 locations of the drainage network in the Fils catchment.

the flow patterns in a given river section are characterised by compact and coherent streamlines, 1-dimensional (1-D) $\mathrm{HN}$-models are considered as adequate for the estimation of flood-water levels and delineation of inundation zones (e.g., Baden-Württemberg, 2005). In cases with more complex river geometries and flow patterns (e.g., at river confluences or other complex flow conditions), 2-dimensional (2-D) models are used for a spatially differentiated hydraulic analysis, especially when local parameters like flow direction, flow velocity, shear stress, etc. are requested. Depending on the intended purposes, both types of models (1-D, 2D) may be applied for stationary flow conditions (e.g., hazard 
assessment for a certain $H Q_{T}$ ) or unsteady flow conditions (e.g., for impact analyses of dike failures).

At the Neckar river (see Fig. 4), the pilot area of this part of the study, a complex flood-information system was set up since the late 1990's (Oberle et al., 2000), consisting of a series of 1-D- and 2-D-HN-models which are interactively connected with a geographical information system (GIS). This system enables the simulation of different flood scenarios in order to evaluate, for example, effects of river engineering measures on flood waves. Through its GIS-interface, the hydraulic results can be superimposed with a high resolution DTM (grid size: $1 \times 1 \mathrm{~m}$ ) to determine inundation zones and respectively the boundaries. The DTM is based on elevation data from different data sources, i.e. terrestrial and airborne surveys. Apart from topographical information, floodrelevant spatial data like flood marks, flood impact area, retention zones and legally defined flood areas, are integrated in the GIS. Linkups to aerial photographs of recent flood events complete the volume of spatial data sets.

With respect to the main target parameters of flood-risk analysis and mapping (water levels, inundation zones/depths) and to the flow characteristics along the Neckar river, a generally 1-dimensional HN procedure was chosen. The choice of this procedure was supported by the fact that the handling of the system and the computing time should match with the size of the study area (approx. 220 river kilometres) and the goal, to install the system as operational tool for daily working practice in the water management authorities. Finally, the calculation of a flood event and the visualisation of inundation depths in the GIS only takes minutes with this system, so that analyses can be realised also based on actual flood forecasts. Some river sections with more complex flow conditions (e.g., tributary mouths) could be assessed only insufficiently by means of an 1-dimensional approach. Here, local 2-D-HN-models were additionally applied. However, a stationary calculation on the base of a 2-dimensional HN procedure requires several hours even using a powerful computer.

The hydrodynamic method of the above mentioned 1dimensional procedure is based on the solution of the Saint-Venant-Equations by an implicit difference scheme (Preissmann-scheme, compare Cunge et al., 1980). Under the normal flow conditions of the Neckar river, this approach is valid and very efficient even for large river sections with respect to data handling, model build-up, model calibration and validation as well as sensitivity analyses and, finally, studies of variants. The functionality of the system includes modelling schemes for looped and meshed river systems as well as for river-regulating structures (e.g. weirs, groins, water power plants). The system geometry of the HN-model, i.e. the discharge area of the main channel and the floodplains, is represented by modified cross sections. The model calibration is done by comparing calculated water levels with surveyed ones. In most sections, water level measurements of different recent flood events are available, thus a calibra- tion and validation for a spectrum of (flood) discharges is possible. A detailed description of the system is given by Oberle (2004).

Areas that contribute to the retention volume of the Neckar river during a flood event are taken into account by a function of storage capacity depending upon the water level. This function can be determined from the digital terrain model by means of several GIS-functionalities and can be verified by comparing calculated with surveyed flood hydrographs.

\subsection{Hydraulic modelling of extreme floods}

In most cases, HN-models are applied to documented flood events from the last decades (in order to assess the present hydraulic conditions) or to statistical flood events with recurrence intervals up to 100 or 200 years (e.g., for delineation of inundation zones or as design events for flood protection measures). With regard to the increasing process complexity, for instance in the case of overtopping or even destruction of a flood protection structure, and to the lack of measurements for the calibration and validation of model parameters for such cases, the application of HN-models to larger floods is rarely practised. However, despite of the uncertainties, it is necessary to apply $\mathrm{HN}$-models for floods that exceed the 100- or 200-year level, as they are the most relevant situations in terms of residual risks, causing severe damages and fatalities. In particular with respect to residual risks, it is obvious that model parameters should also be valid for extreme events. Only the reflection of all physically plausible hazardous situations from the occurrence of first inundations to the maximum possible water levels yields to a comprehensive hazard and risk assessment. This applies equally for flood situations below the design event, as required e.g. for cost-benefit-analyses of protection measures or for the assessment of residual risks due to other failures of technical or non-technical measures (e.g., late installation of mobile protection elements).

Often, historical flood marks indicate much higher water levels than current flood protection level and thus, should serve as realistic reference scenarios for extreme events. In the upper part of the Neckar, the flood with the highest ever recorded water levels occurred in 1824 . The water marks can be found at several buildings in flooded communities giving impressions of the severity of historic floods. They can be taken into account for all flood related planning. With adapted HN-models (discharge-relevant areas, roughness coefficients, etc.) it is possible to assess if similar flood water levels could appear in the present situation.

The present HN-calculations at the Neckar river have confirmed that the historical event 1824 was much higher than today's design flood. Figure 6 shows the calculated maximum water levels of the Neckar river for the 100-year flood ( $H Q_{100}$ ) and the historical flood of 1824 (under actual hydraulic conditions). For example, around the community of Offenau, $98 \mathrm{~km}$ upstream of the confluence of the Neckar 
River with the Rhine River, the historical water level of 1824 was approximately $2.5 \mathrm{~m}$ higher than the dikes that have been built for a 100-year flood.

It has to be emphasised that the consideration of extreme historical events can not only support flood awareness as realised scenarios (under historical conditions), but also used as reference for the analysis of potential extreme cases under present conditions. In this regard, the intention here was not to reconstruct historical hydraulic conditions or to verify historical information in terms of peak discharges. The results shown can help, for example, to assess the probability of flood events that cause comparable water levels in the actual situation. In terms of a reconstruction of historical discharges, a further investigation on historical hydraulic boundary conditions is required (Oberle, 2004). However, due to the limited historical data availability and quality, major uncertainties are expected.

\subsection{Hazard mapping}

The above presented hydrological and hydraulic models, i.e. the regionalization approach for the estimation of extreme events $\left(H Q_{T}\right)$ as well as the GIS-based flood information system for the Neckar river served as basis for the generation of hazard maps with prototype character in a statewide sense. For example, hazard maps for the lower Neckar river (Figs. 4 and 6) are published on the -internet platform (Baden-Württemberg, 2005).

\section{Flood-damage estimation}

\subsection{Basis and objectives}

Based on the knowledge of accumulated values in the areas at risk and relationships between event parameters and resulting damage, flood risks can be identified and quantified, i.e. expected damages for a given flood scenario can be calculated. This information about flood risk for individual buildings, settlement areas and river basins is indispensable to inform the population and stakeholders about the local flood risk, for planning of flood control measures and for benefit-cost analyses of these measures.

The comprehensive determination of flood damage involves both, direct and indirect damage. Direct damage is a damage which occurs due to the physical contact of flood water with human beings, properties or any objects. Indirect damage is a damage which is induced by the direct impact, but occurs - in space or time - outside the flood event. Examples are disruption of traffic, trade and public services. Usually, both types are further classified into tangible and intangible damage, depending on whether or not these losses can be assessed in monetary values (Smith and Ward, 1998). Although it is acknowledged that direct intangible damage or indirect damage play an important or even dominating role in evaluating flood impacts (FEMA, 1998; Penning-Rowsell

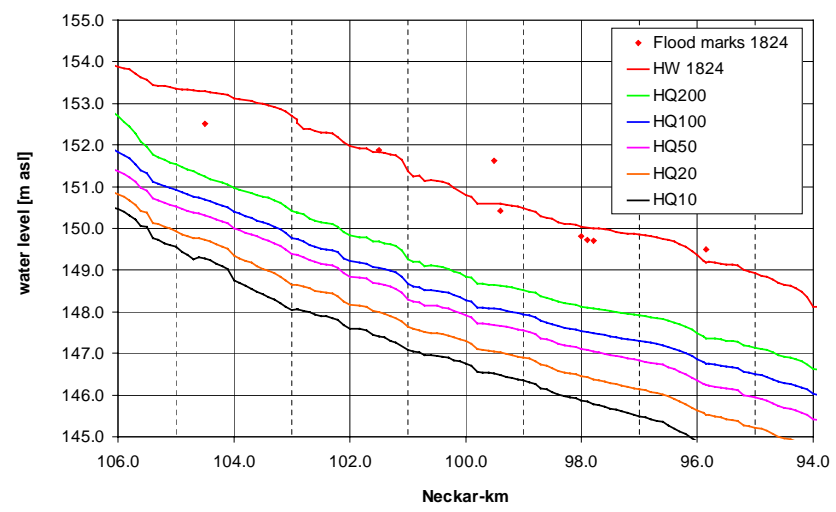

Fig. 6. Maximum water levels along the Neckar river for statistical flood events $H Q_{T}$ with $T=10,20, \ldots, 200$ years) and the historical event 1824 (HW1824), the latter as reconstructed from water-level marks. Note location of the community Offenau at the river Neckar (98 km upstream of the confluence with the river Rhine).

and Green, 2000), the largest part of the literature on flood damage concerns direct tangible damage (Merz and Thieken, 2004). The present study is limited to direct monetary flood damage to buildings and contents of private households.

As outlined above, stage-damage-functions for different building types or building uses are an internationally accepted standard approach for flood damage estimation. While the outcome of most stage-damage functions is the absolute monetary loss to a building, some approaches provide relative depth-damage functions, determining the damage e.g. in percentage of the building value (e.g. Dutta et al., 2003). If these functions are used to estimate the loss due to a given flood scenario property values have to be predetermined (Kleist et al., 2004, 2006). However, using these functions, one has to be aware that the damage estimation is generally associated with large uncertainties as recent studies asserted (Merz et al., 2004). One approach to reduce the uncertainty connected with stage-damage functions is their specific adjustment to the area of interest (Buck and Merkel, 1999). This strategy was followed here, supported by intensive on-site investigations of the building structure in some pilot areas along the Neckar river.

Recent flood events have shown that during slowly rising river floods the maximum water level during the flood event is responsible for the resulting damage. In these cases, the gradient of the flood wave is small and for this reason there are no damaging effects due to flow velocity impacts. Major damages are caused by wetting of contents and building structure in the cellar and the ground floor. This does not apply for flash floods e.g. in mountainous areas where, due to high flow velocity, buildings may collapse partly or totally. Therefore, it is obvious that flood damage depends, in addition to building type and water depth, on many factors which are not considered using stage-damage functions. One factor is the flow velocity, but there are also others like the 
duration of inundation, sediment concentration, availability and information content of flood warning, and the quality of external response in a flood situation (Smith, 1994; PenningRowsell et al., 1994; USACE, 1996). Although a few studies give some quantitative hints about the influence of some of the factors (McBean et al., 1988; Smith, 1994; Wind et al., 1999; Penning-Rowsell and Green, 2000; ICPR, 2002; Kreibich et al., 2005), there is no comprehensive approach to consider these factors in a loss-estimation model. Using actual flood damage data from the 2002 flood in Germany, we followed this idea here and developed a multifactorial approach for damage estimation.

The flood-damage estimation can be undertaken on different levels of spatial differentiation:

- On local scale, the damages can be estimated based on spatial data and stage-damage-functions for individual buildings or land parcels. In Germany, commonly the Automated Real Estate Map (ALK) is used for these assessments. The ALK data show the base-area of the single buildings and give their specific use (e.g. residential building, commercial building, stable, garage).

- On a more aggregated level, the approach can be based on statistical information about population, added values, business statistics or capital assets for land-use units. These values are published yearly by responsible state authorities (statistical offices). Commonly data from the Authoritative Topographic-Cartographic Information System (ATKIS) is used for this approach in Germany. The ATKIS data differentiate more than 100 types of land-use (e.g. residential area, power plant, sports facilities).

- Large-scale analyses may be carried out for larger landuse units, like communities or ZIP-code areas, considering that they may be only partially flooded. These analyses are often based on the CORINE land cover data (Coordinated Information on the European Environment). The CORINE data differentiates 45 different types of land-use (e.g. continuous urban fabric, industrial or commercial units, agro-forestry areas).

During the last years, the computational power increased in a way that today flood damage analyses even for larger river courses can be undertaken with a high level of detail. In this context, the question of spatial scale of damage analysis is moving from limitations concerning the area size to limitations concerning the quality respectively the level of detail of available spatial data sets.
4.2 Flood damage estimation on local scale based on stagedamage curves

\subsubsection{GIS-based damage analysis (tool)}

As discussed above, it is commonly required in flood-risk assessment to locate accessible information about hazard and vulnerability at a high spatial resolution (e.g. for cost-benefit analyses, for local protection measures, rating of risks for insurance purposes). In view of these practical requirements, a GIS-based tool for damage estimation was developed in the present project. This tool supplements the above mentioned flood information system at the Neckar river, i.e. it builds directly on the water level information for individual endangered objects based on hydrodynamic calculations.

The GIS-based tool for damage estimation on local scale uses the following procedure.

- Selection of the project area (spatial, postcodes or areas of communities).

- Identification and categorization of each building in the project area (based on ALK-Data)

- Estimation of the flood-sill for each structure (lowest damaging water level).

- Estimation of the ground-floor elevation (floor above the cellar).

- Estimation of the values for building-structure and contents (fixed/mobile inventory).

- Estimation of the stage-damage-functions, differentiated for different types of buildings, cellar/floor, building structure/contents.

- Calculation of the water-level for each object in the area.

- Estimation of the damages to buildings and contents for different water-levels based upon the type and use of each building.

The tool provides the selection of the project area on the base of different spatial or administrative areas: barrages, communities or postcodes. The area of interest or spatial objects can be selected from tables or as graphical selection in the GIS.

For the damage estimation, the water depth close to or inside the object is the determining factor. With the HN-modelling in connection with the digital terrain model (DTM) the water depths above the terrain is calculated. The assumption that the damaging water depth inside the object is the same as the depth over terrain is correct if the ground floor elevation has the same elevation as the surrounding territory and if there are no protection measures. In this case, the relevant elevation of the object basis can be calculated on the base of the DTM as the mean value of the terrain altitude on the buildings base. A second option in the tool is to enter 
the ground floor elevation and the height of the flood-sill for each single object. Thus, local object features and protection measures can be considered.

The damage estimation is based on the general assumption that the monetary damage depends on the type and use of the building. One of the basic studies was performed by Penning-Rowsell and Chatterton (1977). In the Blue manual, stage-damage functions for residential buildings in the UK were derived for age and type of the buildings, the duration of the flood event and the social class of the inhabitants. The damages are differentiated for building fabric and contents. Other similar international studies were done by Wind et al. (1999); Smith (1994); Parker et al. (1987). In Germany, in the HOWAS database, some 3600 single damage cases for different objects are included. The damage data were collected after different flood events in Germany. Analyses by Buck and Merkel (1999) showed that for practical uses, damage estimation with a root function provides reasonable results.

Due to the fact that the absolute damage depends on a variety of factors being specific for every single building or land parcel, a meaningful damage estimation can be expected from the application of such stage-damage functions and their adaptation for individual objects or - in terms of exposure and vulnerability - uniform spatial units. For that reason, the possibility to apply different functions was implemented in this software module, where the user can choose at least one of the three following function types: 1. Linear Polygon Function, 2. Square-Root Function, or 3. Pointbased Power Function.

\section{- Linear Polygon Function}

The user interface allows to enter 5 pairs of variates $(\mathrm{hi} / \mathrm{Si})$ of water-depth and damage, which are interpolated sectional with linear functions. Between the minimum $(i=1)$ and maximum $(i=5)$ pair, the function can be noted:

$S=S_{i}+\left(\frac{S_{i+1}-S_{i}}{h_{i+1}-h_{i}}\right) \times\left(h-h_{i}\right), h_{i} \leq h<h_{i+1}$

where $\mathrm{S}=$ estimated damage, $S_{i}, h_{i}=$ user-defined nodes of the function, $\mathrm{h}=$ water depth.

The first pair of variates $\left(h_{1} / S_{1}\right)$ defines the minimum water depth below which the damage is zero. The last point $\left(h_{5} / S_{5}\right)$ sets the possible maximum damage; for water depths above the damage stays constant. The Polygon function (3) allows a simple adaptation to individual damage symptoms of different types of objects.

\section{- Square-Root Function}

In practical view, square-root stage-damage functions provide good results for damage estimation (Buck and Merkel, 1999). Therefore, a square-root function is implemented in

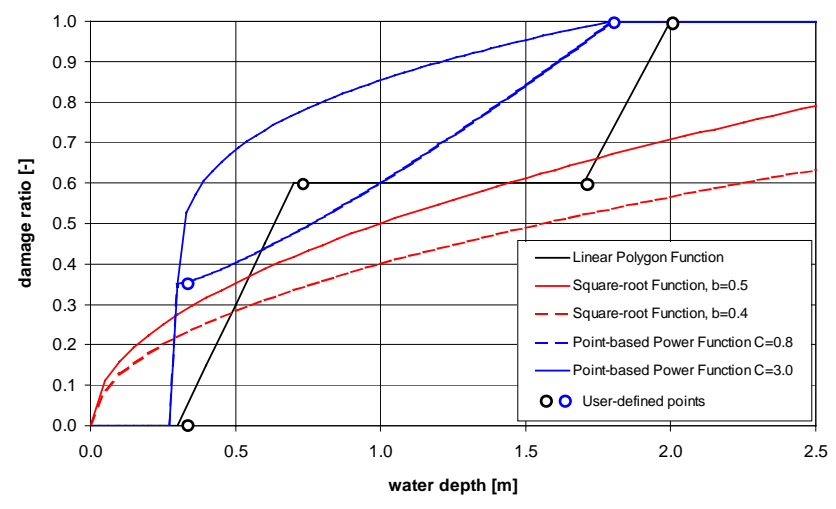

Fig. 7. Examples of function types used in the GIS-based damage analysis tool.

the damage estimation tool as second function type, where the parameter $b$ is user-defined:

$S=b \times \sqrt{h}$

with $S=$ estimated damage, $h=$ water depth, $b=$ user-defined parameter.

The parameter $b$ characterises the damage for $h=1 \mathrm{~m}$. Hence, using Eq. (4), the damage progression can be described with only one parameter. For the sample damage estimation in this paper (see below), the damage functions for different building types in the project area were chosen based on the flood-damage database HOWAS (Buck and Merkel, 1999).

\section{- Point-based Power Function}

In some cases, damage does not occur until the stage rises to a threshold height in the building. For example in rooms or storeys, where floors and walls are tiled, damage can be negligible until the water level affects the electrical installation (power sockets). On the other hand, the maximum damage is often obtained, when the contents are submerged; a further rise of the water level does not increase the damage in a relevant manner. For these cases, a power function can be chosen in the tool, where the points of first and maximum damage as well as the exponent $C$ determining the gradient of the function can be individually defined.

$S=S_{\max } \times\left[\frac{S_{0}}{S_{\max }}+\left(1-\frac{S_{0}}{S_{\max }}\right) \times\left(\frac{h-h_{0}}{h_{\max }-h_{0}}\right)^{\frac{1}{C}}\right]$

with $S=$ =stimated damage, $h=$ water depth, $\left(h_{0} / S_{0}\right)=$ point of first damage, $\left(S_{\max } / h_{\max }\right)=$ point of maximum damage, $C=$ user-defined exponent.

The three function types (Eqs. 3-5) are exemplified in Fig. 7.

The creation, editing, and choice of these three functions are realised by different masks that allow the user to conveniently handle the input. For the Polygon and the Power 
Table 2. Standardized damage to buildings and inundated areas for the test community.

\begin{tabular}{cccccc}
\hline $\begin{array}{c}\text { Exceedance } \\
\text { probability [\%] }\end{array}$ & \multicolumn{2}{c}{ Affected buildings [-] } & \multicolumn{2}{c}{ Inundated area [m ${ }^{2}$ ] } & Standardized \\
residential & total & residential & settlement & damages [\%] \\
\hline 10 & 4 & 8 & 4000 & 6000 & 0.002 \\
5 & 14 & 40 & 15000 & 29000 & 0.01 \\
2 & 71 & 126 & 41000 & 71000 & 53 \\
1 & 127 & 242 & 81000 & 129000 & 100 \\
0.50 & 223 & 378 & 143000 & 220000 & 194 \\
0.20 & 237 & 403 & 156000 & 237000 & 215 \\
0.10 & 266 & 447 & 174000 & 267000 & 255 \\
0.05 & 296 & 496 & 192000 & 298000 & 304 \\
0.02 & 328 & 540 & 203000 & 326000 & 364 \\
0.01 & 342 & 571 & 207000 & 341000 & 400 \\
\hline
\end{tabular}

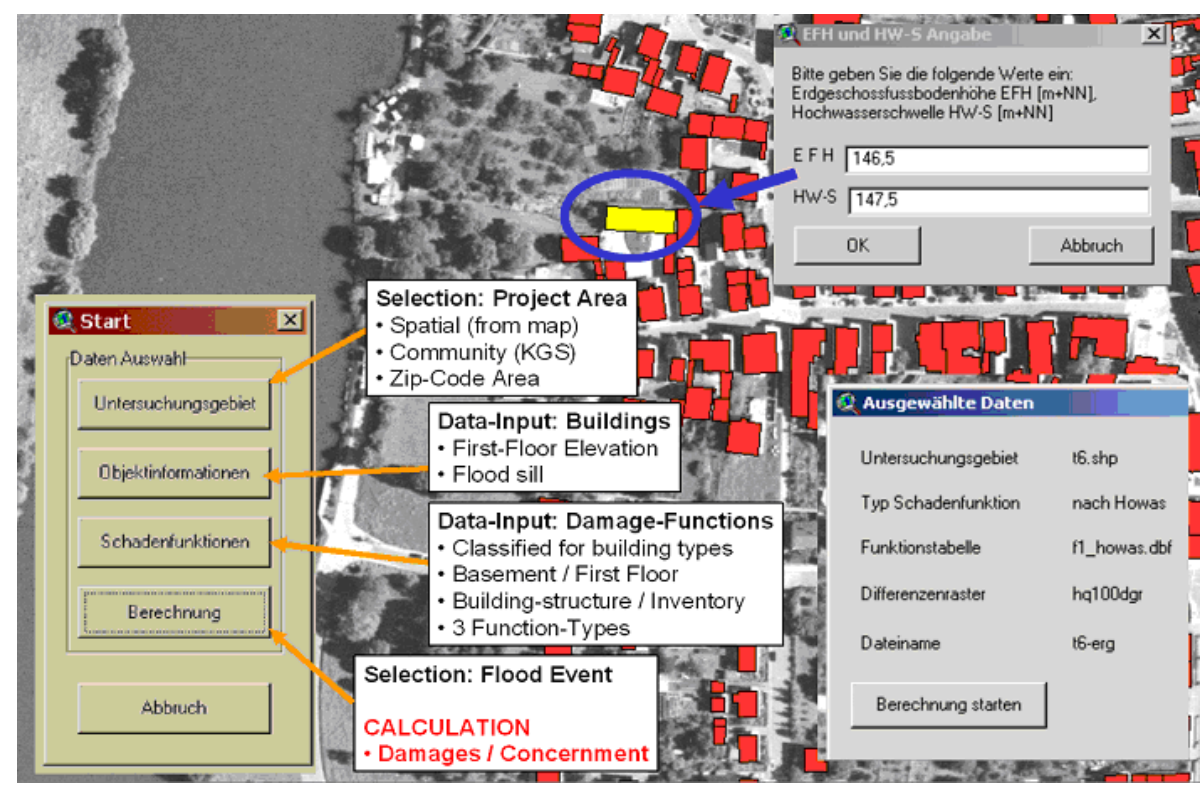

Fig. 8. GIS-based damage analysis tool (screenshot of graphical user interface). The damage or the general involvement can be calculated by selecting the area of interest, land-use and event information and damage-relevant factors.

function types, the damage can be calculated in absolute monetary units (EUR) or percentages of damage.

Before starting the calculation, a flood event must be selected. According to the coupling of the damage estimation tool to the flood information system for the Neckar river, the outcomes of the hydraulic calculations, i.e. water surfaces, can be directly used as input of the damage estimation. The implementation of the damage estimation tool in a GISsoftware environment is realised in four dialogue modules shown in Fig. 8.

Hence, the GIS-based damage estimation tool enables the user to assess the flood damage to single buildings in floodprone areas and the spatial aggregation of the event-specific damage for a defined group of buildings or areas. Figure 9 shows the calculated damage values for a test community for a range of events, beginning from the flood causing the first damage up to the 1000-year event. The damage values in Fig. 9 are standardized to the 100-year event. That means for example, that the damage caused by the 1000 -year flood is approximately 2.6 times higher than the one caused by the 100 -year event.

Furthermore, the tool includes functionalities to cope with cases where detailed land-use data (e.g. ALK) are not available or where the assessment could be simplified. As revealed in Table 2, it is possible to make assumptions e.g. about the number of affected houses in flood-prone areas, in order to give an overview on flood risk without explicitly calculating monetary damage. For damage calculations on a more aggregated spatial level, the values at risk can be derived from statistical data for administrative districts 
and related to their spatial unit $\left(\mathrm{EUR} / \mathrm{m}^{2}\right)$. In this case, the damage estimation can be delivered by spatial intersection of flood-hazard information (inundation zone) with land-use data (e.g. ATKIS) in order to calculate the extension of the inundated settlement area (see columns 4 and 5 in Table 2).

Usually, the flood-damage calculation is provided for costbenefit analyses of flood protection measures. For this purpose, the costs of a flood-protection measure can be compared to its benefit, i.e. the avoided damage up to the design event respectively the residual risk after the implementation of the measure, normally expressed as mean annual damage (MAD). For the above mentioned sample community, a dike designed for a 100 -year event provides a significant reduction of MAD, but the residual risk due to a larger flood event still accounts for approximately 40 percent of the original value.

The main advantage of the presented damage estimation on a local scale is that the damage-determining factors are given both on the hazard side (being in general the water depth) as well as on the side of vulnerability (stage-damage functions for individual objects). For estimations on an aggregated spatial level, where areas of the same building type may be defined (e.g. ATKIS-data) but no information on individual objects is available, one has to make assumptions on the spatial distribution of buildings and building types. Furthermore, as the water depth in an inundated area varies in space, the definition of the damage-determining water level gets more uncertain with increasing spatial units. Thus, using stage-damage functions, one has to define the damagerelevant depth or use a statistical approach to estimate the spatial distribution.

4.3 Development of a multifactorial approach for damage estimation

\subsubsection{Damage data of the extreme flood in August 2002}

Since flood damage is also influenced by other factors besides the water depth, more knowledge about the connections between actual flood losses and damage-determining factors is needed for the improvement of damage estimation. Therefore, during April and May 2003 in a total of 1697 private households along the Elbe River, the Danube River and their tributaries, people were interviewed about the flood damage to their buildings and household contents caused by the August 2002 flood as well as about flood characteristics, precautionary measures, warning time, socio-economic variables, regional and use-specific factors. The 2002 flood was an extreme event, e.g., with a discharge return period of 150-200 years at the river Elbe in Dresden and with a return period of 200-300 years at the river Mulde in Erlln (IKSE, 2004). Detailed descriptions were published by e.g. DKKV (2003), Engel (2004), IKSE (2004). The total damage in Germany is estimated to be 11.6 billion. The most affected federal state was Saxony where the total flood damage is estimated to be 8.6 billion (BMI, 2002; SSK, 2003). In the affected areas,

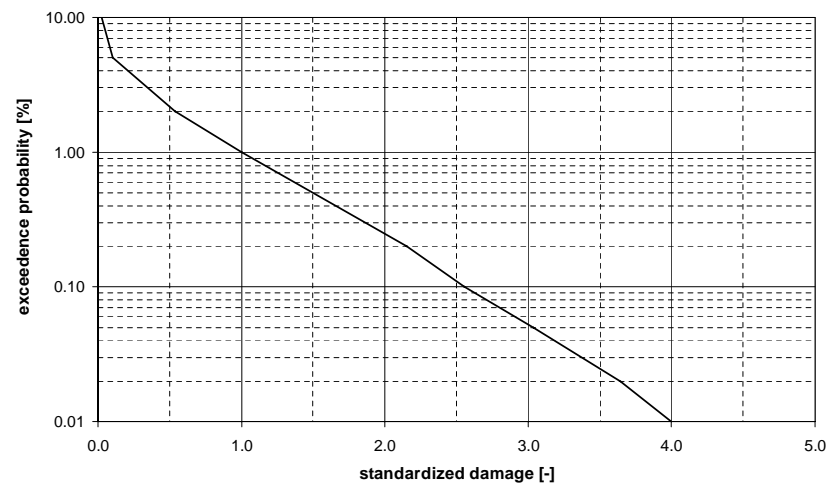

Fig. 9. Standardized damage to residential buildings in a test community for annual exceedance probabilities from 0.1 to 0.0001 (i.e. damage to a 100 -year flood $=1$, situation without flood protection measure).

a building-specific random sample of households was generated, and always the person with the best knowledge about the flood damage in a household was interviewed. An interview comprised around 180 questions and lasted about $30 \mathrm{~min}$. The computer-aided telephone interviews were undertaken by the SOKO-Institute, Bielefeld. Detailed descriptions of the survey were published by Kreibich et al. (2005) and Thieken et al. (2005).

Statistical analysis was undertaken with the software SPSS for Windows, version 11.5.1. and Matlab, version 7.0.1. Since a big share of the resulting data show skewed distributions, the mean and the median are given. Significant differences between two independent groups of data were tested by the Mann-Whitney-U-Test, for three or more groups of data the Kruskal-Wallis-H-Test was applied. For all tests a significance level of $\mathrm{p}<0.05$ was taken.

\subsubsection{Factors influencing the flood damage}

Flood damage influencing factors can be divided into impact factors like water depth, contamination, flood duration, flow velocity and resistance factors like type of building, preventive measures, preparedness, and warning (Thieken et al., 2005).

During the extreme flood in August 2002, for example, contamination led to significantly higher damage ratios (fraction of the flood damage in relation to the total value) to buildings and contents (Fig. 10). The damage ratio of contents was increased by $93 \%$ for high contamination in comparison with no contamination. For building damage it was increased by more than 200\%. During the 1999 flood in Bavaria oil contamination on average led to a three times higher damage to buildings, in particular cases even to total loss (Deutsche Rück, 1999).

On the resistance side, private precautionary measures significantly reduce the flood loss even during an extreme flood like the one in 2002 (Fig. 11). The damage ratio of contents 

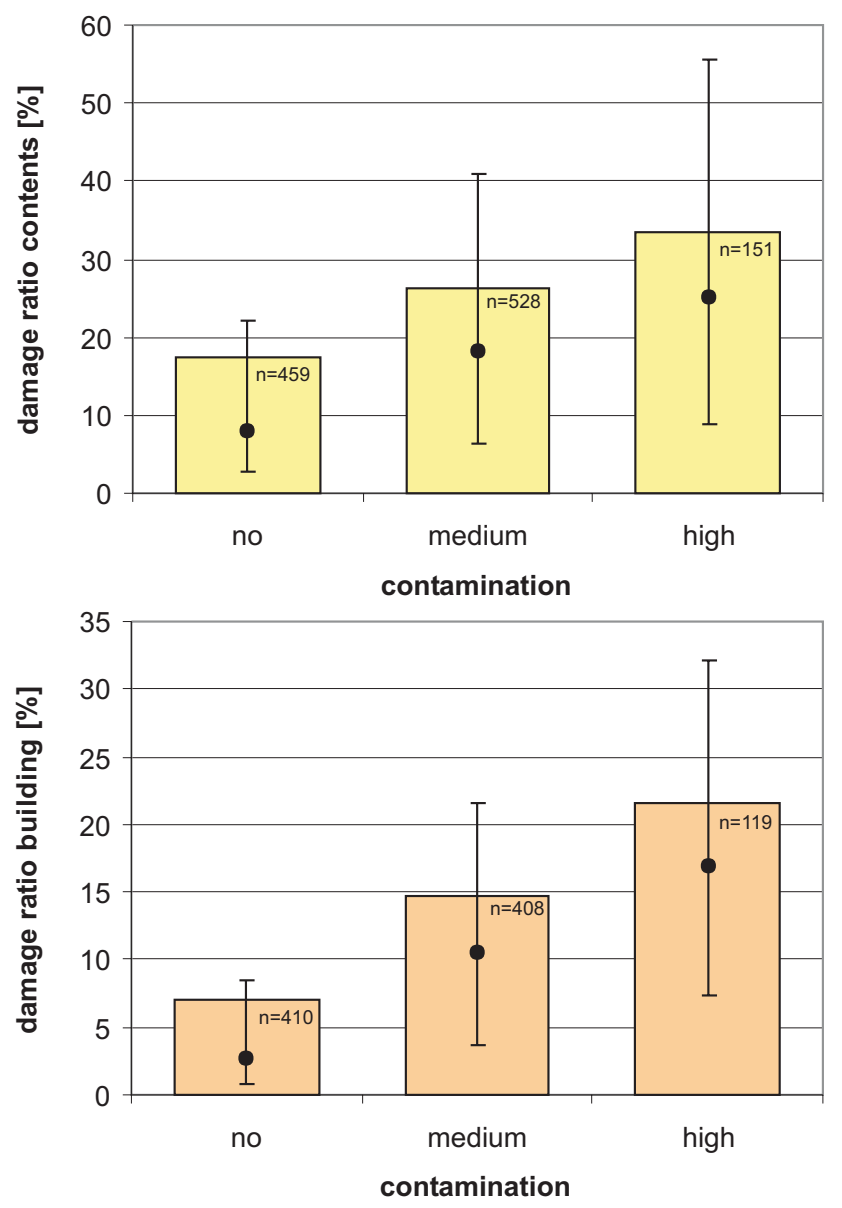

Fig. 10. Damage ratios of residential buildings and contents influenced by different levels of contamination. The contamination classes "medium" and "high" take into account the type of contamination (e.g. chemicals, sewage, oil) and if single, double or triple contaminations occurred (bars=means; dots=medians and $25-75 \%$ percentiles).

was reduced by $55 \%$ for very good precautionary measures in comparison with no measures. For building damage it was decreased by $63 \%$. This positive effect of precautionary measures is noteworthy since it is believed that these measures are mainly effective in areas with frequent flood events and low flood water levels (ICPR, 2002). An investigation of single precautionary measures revealed flood adapted use and furnishing as the most effective measures during the extreme flood in August 2002 (Kreibich et al., 2005). They reduced the damage ratio for buildings by $46 \%$ and $53 \%$, respectively. The damage ratio for contents was reduced by $48 \%$ due to flood adapted use and by $53 \%$ due to flood adapted furnishing. The International Commission for the Protection of the Rhine gives a good overview on the effects of private precautionary measures in their report "Non Structural Flood Plain Management - Measures and their Effectiveness" (ICPR, 2002).
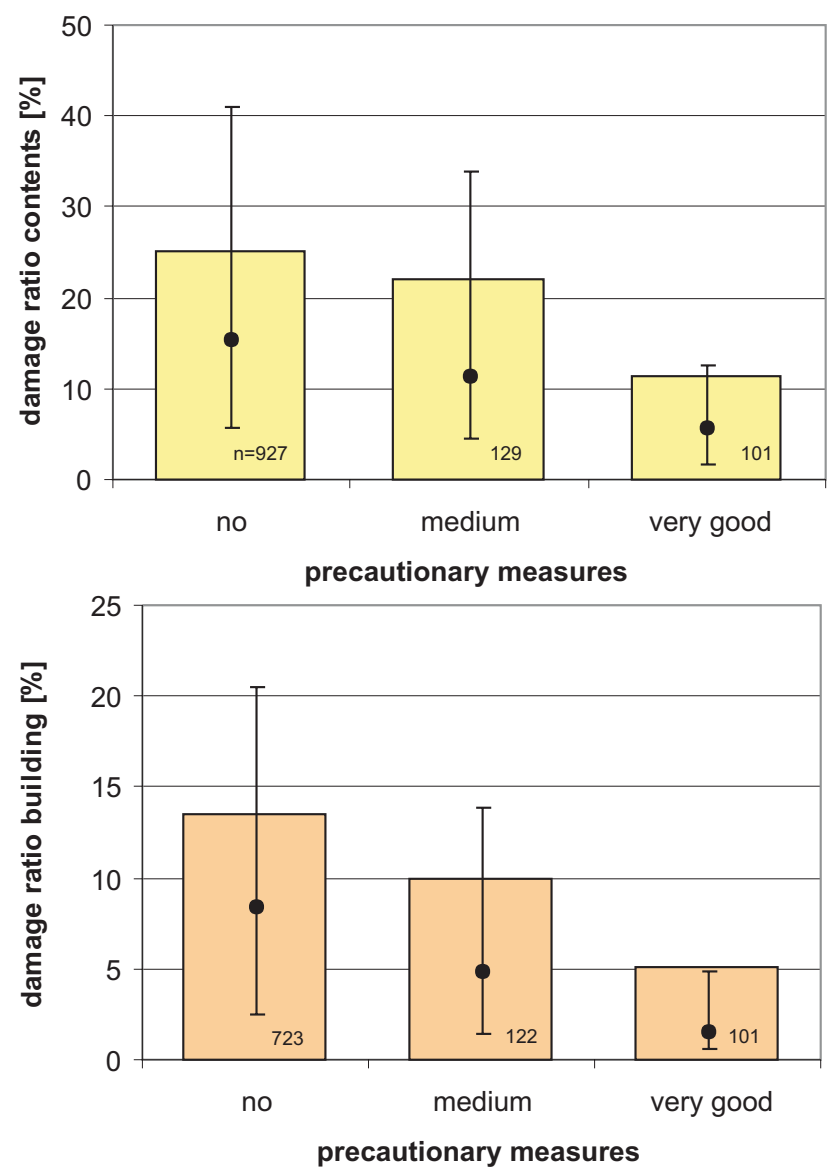

Fig. 11. Damage ratios of residential buildings and contents influenced by different levels of precautionary measures. The precaution classes "medium" and "very good" take into account the type of precaution (e.g. informational precaution, adapted use, water barriers) and how many precautionary measures have been applied $($ bars $=$ means; dots $=$ medians and $25-75 \%$ percentiles).

Interestingly, flow velocity was not identified as one of the main damage influencing factors. As well, a comprehensive study about the main factors influencing flood damage to private households after the 2002 flood revealed, that flood impact variables (e.g., water level, contamination) were the factors mostly influencing building as well as content damage (Thieken et al., 2005). Flow velocity, however, influenced the damage to a small fraction. Also during a survey about the impact of six flood characteristics on flood damage, building surveyors in the United Kingdom assessed flow velocity to be the least important factor (Soetanto and Proverbs, 2004). Since it is known that flow velocity plays a crucial role in mountainous regions, it should be further investigated whether it will be identified as a main influencing factors, if the damage cases are divided in accordance to the dominating flood type (i.e. flash flood and slowly rising river flood). 
Table 3. Statistical characterisation of damage ratios of buildings (upper value) and contents (lower value in brackets) of the sub-samples "medium quality of buildings".

\begin{tabular}{|c|c|c|c|c|c|c|c|}
\hline \multirow[t]{2}{*}{ Building type } & \multirow{2}{*}{$\begin{array}{c}\text { Water depth } \\
\text { classified }[\mathrm{cm}]\end{array}$} & \multicolumn{6}{|c|}{ Damage ratio building (contents) } \\
\hline & & Mean & $\mathrm{CV}^{*}$ & median & $25 \%$-perc & $75 \%$-perc & $\mathrm{n}$ \\
\hline \multirow{10}{*}{$\begin{array}{l}\text { one-family } \\
\text { house }\end{array}$} & $<21$ & 0.04 & 1.56 & 0.02 & 0.01 & 0.04 & 133 \\
\hline & & $(0.10)$ & (1.23) & $(0.05)$ & $(0.02)$ & $(0.13)$ & (102) \\
\hline & $21-60$ & 0.07 & 1.07 & 0.04 & 0.02 & 0.09 & 42 \\
\hline & & $(0.19)$ & $(0.97)$ & $(0.13)$ & $(0.06)$ & $(0.23)$ & (47) \\
\hline & $61-100$ & 0.10 & 0.95 & 0.08 & 0.04 & 0.13 & 44 \\
\hline & & $(0.35)$ & $(0.87)$ & $(0.24)$ & $(0.10)$ & $(0.52)$ & (49) \\
\hline & $101-150$ & 0.22 & 0.71 & 0.19 & 0.10 & 0.32 & 54 \\
\hline & & $(0.50)$ & $(0.59)$ & $(0.46)$ & $(0.25)$ & $(0.76)$ & (63) \\
\hline & $>150$ & 0.24 & 0.70 & 0.22 & 0.13 & 0.33 & 84 \\
\hline & & $(0.54)$ & $(0.56)$ & $(0.56)$ & $(0.34)$ & $(0.75)$ & (104) \\
\hline \multirow{10}{*}{$\begin{array}{l}\text { terraced and } \\
\text { semi-detached } \\
\text { houses }\end{array}$} & $<21$ & 0.03 & 1.44 & 0.02 & 0.00 & 0.05 & 55 \\
\hline & & $(0.08)$ & $(0.94)$ & $(0.06)$ & $(0.02)$ & $(0.12)$ & (44) \\
\hline & $21-60$ & 0.08 & 0.88 & 0.06 & 0.03 & 0.11 & 19 \\
\hline & & $(0.26)$ & $(0.98)$ & $(0.16)$ & $(0.08)$ & $(0.43)$ & (23) \\
\hline & $61-100$ & 0.11 & 0.77 & 0.09 & 0.04 & 0.13 & 16 \\
\hline & & $(0.27)$ & $(0.87)$ & $(0.16)$ & $(0.11)$ & $(0.35)$ & (21) \\
\hline & $101-150$ & 0.18 & 0.68 & 0.12 & 0.08 & 0.25 & 17 \\
\hline & & $(0.45)$ & $(0.65)$ & (0.37) & $(0.22)$ & $(0.54)$ & (21) \\
\hline & $>150$ & 0.22 & 0.73 & 0.17 & 0.10 & 0.32 & 49 \\
\hline & & $(0.54)$ & $(0.56)$ & $(0.49)$ & $(0.31)$ & $(0.86)$ & (58) \\
\hline \multirow{10}{*}{$\begin{array}{l}\text { apartment } \\
\text { building }\end{array}$} & $<21$ & 0.03 & 1.70 & 0.01 & 0.00 & 0.03 & 70 \\
\hline & & $(0.10)$ & $(1.72)$ & $(0.03)$ & $(0.01)$ & $(0.10)$ & (55) \\
\hline & $21-60$ & 0.10 & 1.24 & 0.05 & 0.03 & 0.11 & 33 \\
\hline & & $(0.18)$ & (1.23) & $(0.11)$ & $(0.06)$ & $(0.21)$ & (36) \\
\hline & $61-100$ & 0.11 & 1.04 & 0.05 & 0.02 & 0.16 & 20 \\
\hline & & $(0.29)$ & $(0.92)$ & $(0.22)$ & $(0.08)$ & $(0.48)$ & (57) \\
\hline & $101-150$ & 0.13 & 1.01 & 0.10 & 0.04 & 0.15 & 34 \\
\hline & & $(0.29)$ & $(0.92)$ & $(0.22)$ & $(0.08)$ & $(0.48)$ & (57) \\
\hline & $>150$ & 0.18 & 1.04 & 0.12 & 0.06 & 0.25 & 45 \\
\hline & & $(0.34)$ & $(0.94)$ & $(0.19)$ & $(0.08)$ & $(0.57)$ & $(62)$ \\
\hline
\end{tabular}

* CV: coefficient of variance

\subsubsection{An approach for an improved damage estimation}

Based on the above mentioned studies about damageinfluencing factors and the finding that the more factors are specified, the lower the coefficient of variation within the data is (Büchele et al., 2004), the following multifactorial approach for damage estimation was developed. The damage data of the 1697 interviewed households after the 2002 flood was first divided into sub-samples according to the damage influencing factors water level, building type (one-family house (ofh), terraced and semi-detached houses (tsh), apartment building (ab)) and quality of building (Table 3). Since not all sub-classes for "very good quality of building (vg)" were filled, the statistics for "medium quality (m)" were calculated and a mean loading factor for all water levels was estimated for the "very good quality". Accordingly, for each flood affected building it has to be decided to which subclass it belongs to so that its probable damage can be calculated using the mean damage ratio of the respective subclass (Fig. 12). Data variability within the sub-samples (coefficients of variation (CV)), and therefore the uncertainty when applying the mean damage ratio as an estimate, were highest for shallow water levels and apartment buildings (Table 3). This might be due to large differences between buildings concerning the quality of cellar contents and the water level above which damage occurs. This threshold depends strongly on the location and shielding of cellar windows, the level of the ground floor, interior accessories etc. Generally, apartment buildings might be more heterogeneous in size and value than one-family houses. This tendency in data variability was the same for damage ratios of building and contents whereas the data variability was generally slightly 

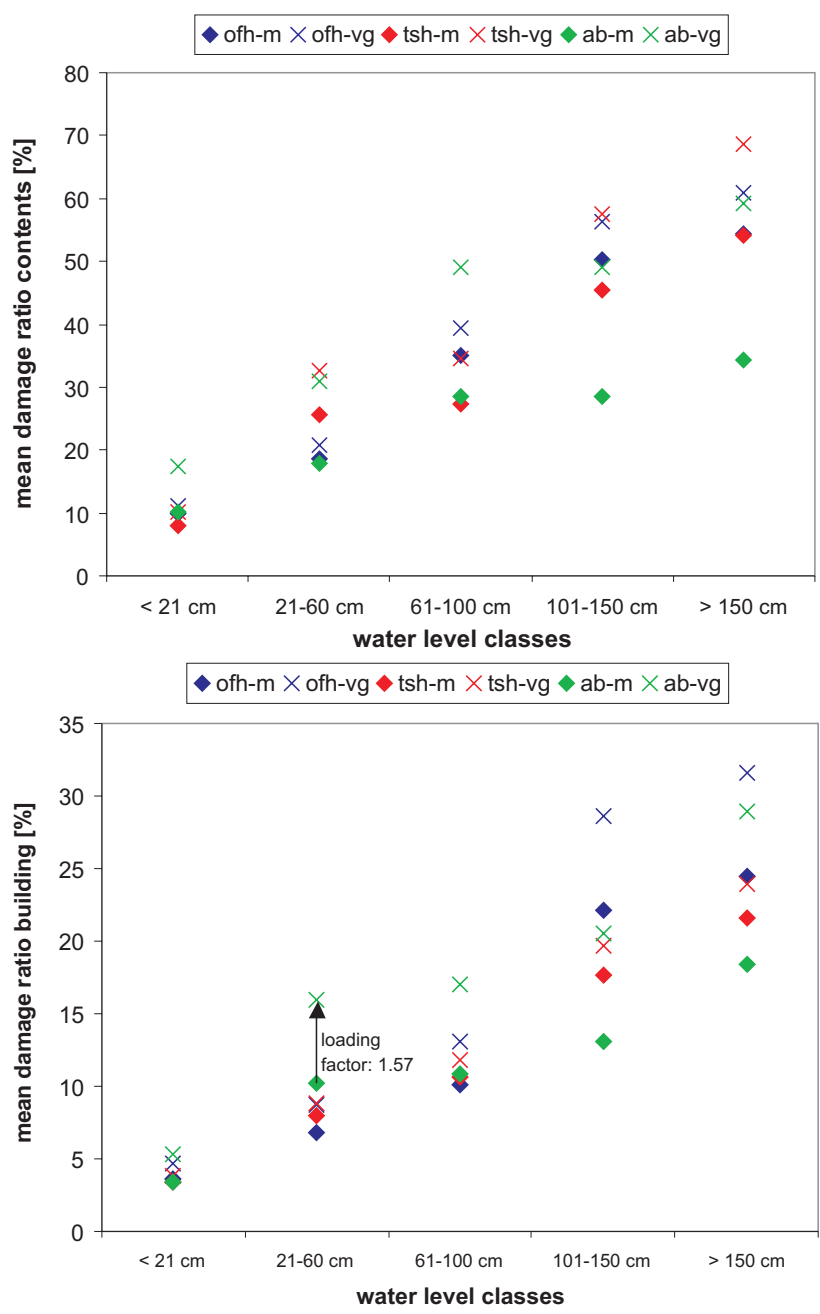

Fig. 12. Mean damage ratios of buildings and contents of all subsamples (ofh-m: medium quality one-family houses, ofh-vg: very good quality one-family houses, tsh-m: medium quality terraced and semi-detached houses, tsh-vg: very good quality terraced and semi-detached houses, ab-m: medium quality apartment buildings, ab-vg: very good quality apartment buildings). The values for the "very good quality houses (vg)" were calculated with separate loading factors for building (ofh: 1.29, tsh: 1.11, ab: 1.57) and contents damage (ofh: 1.12, tsh: 1.27, ab: 1.72).

smaller for contents damage (Table 3). The CVs were in the same range as the ones of the HOWAS data base, the most comprehensive flood damage data base in Germany, which has CVs of $155 \%$ and $149 \%$ for total flood damage of private households with flooded cellars only and with flooded storeys, respectively (Merz et al., 2004).
The difference in damage ratios between the building types and qualities was smallest for lowest water levels (Fig. 12). This is probably explained by relatively homogeneous interior fittings and objects stored in the cellars of all building types. A similar trend was also observed by McBean et al. (1988) who differentiated the three water levels $-1.8 \mathrm{~m}$, $0.6 \mathrm{~m}, 2.4 \mathrm{~m}$. Damage ratios of contents are very similar to the ones used in a study in the Rhine catchment and also the trend of higher contents damage in one-family houses in comparison to apartment buildings is the same (MURL, 2000). In contrast, estimates of building damage are lower in the "Rhine study", which uses linearly increasing damage ratios of buildings from $1 \%$ at a water level of $50 \mathrm{~cm}$ to $10 \%$ at a water level of $5 \mathrm{~m}$ (MURL, 2000).

Similarly, via the comparison of the sub-samples of different levels of contamination and precautionary measures, loading factors for these cases were calculated (Table 4). The concept of loading or adjustment factors for flood damage curves was already developed by McBean et al. (1988) who calculated adjustment factors for flood warning, longduration floods and floods with high velocities or ice. Unfortunately a differentiation between the building types was not possible here, due to a lack of data. Since only a very limited number of households which had undertaken precautionary measures experienced high contamination $(\mathrm{n}=21)$, it is suspected that precautionary measures are largely able to avoid contamination and these cases can be neglected.

This approach seems promising to significantly reduce the uncertainty in damage estimation where no individual on-site investigations are possible. However, it needs further investigation and validation.

\section{Conclusions}

Flood management and consequently flood mapping is a key task and ongoing development in the sphere of competency of state authorities in Germany. To support this demanding target from the scientific side, especially aiming at a more reliable flood-risk assessment, these studies were focussed on the improvement of the following methods: 1.'The estimation of extreme events which exceed the design flood of flood protection measures, 2. The assessment of flood hazard and risk over the whole spectrum of possible damagerelevant flood events, 3 . The damage estimation via the consideration of various building- and event-specific influences on the resulting damage. In detail, a regionalization approach for flood peak discharges was further developed and substantiated, especially regarding recurrence intervals of 200 to 10000 years and a large number of small ungauged catchments. The hydraulic simulation presented provides hazard mapping covering the whole spectrum of relevant flood events, with special reference to extreme historical floods, and is directly coupled with a GIS-tool for flood damage assessment based on established stage-damage functions. In 
Table 4. Loading factors for different levels of contamination and precautionary measures.

\begin{tabular}{lcc}
\hline & \multicolumn{2}{c}{$\begin{array}{c}\text { Loading factors for } \\
\text { damage ratios of }\end{array}$} \\
\hline No contamination and no precautionary measures & buildings & contents \\
No contamination and medium precautionary measures & 0.92 & 0.90 \\
No contamination and very good precautionary measures & 0.41 & 0.85 \\
Medium contamination and no precautionary measures & 1.20 & 0.64 \\
Medium contamination and medium precautionary measures & 0.86 & 0.99 \\
Medium contamination and very good precautionary measures & 0.71 & 0.73 \\
High contamination and no precautionary measures & 1.58 & 1.44 \\
\hline
\end{tabular}

addition, the newly developed multifactorial approach for damage estimation considers more damage influencing factors besides the water depth, like building quality, contamination and precautionary measures.

Flood hazard and risk assessment is actually practised with an increasing level of detail and accuracy for more and more areas, especially in regions which are frequently or were recently affected by floods, like Baden-Württemberg. In this regard, it is on the one hand self-evident that flood hazard and risk, in particular the residual risk of flood protection measures, must be assessed on a level of detail which supports local planning and precaution. Furthermore, as hazard and vulnerability are not constant in time, corresponding analyses and maps must be updated after significant changes with a minimum of additional expenses. The presented information systems and analysis tools are a base for these purposes, not only for our specific study areas. On the other hand, as discussed, flood hazard and risk assessment is still associated with large uncertainties, even in areas where a rather good data and model base is available (as for example given at the Neckar river by means of the flood information system with relatively well-known hydraulic conditions and substantial spatial data). Considering that integrated flood-risk management implies decisions under uncertainty, the effectiveness of detailed risk analyses has to be critically reflected. This can be done in further pilot studies where the role of different sources of uncertainty in the overall risk assessment procedure can be analysed (e.g., Apel et al., 2004). However, the level of detail of such uncertainty and risk analyses has to be defined for the individual case, i.e. for the specific area of interest, planned protection measure, etc. For floodhazard mapping as proceeding task of practitioners in an area-wide sense, standard methods and simplifications must be accepted, as long as they can be reasoned by other aspects of a comprehensive flood-risk management (e.g., spatial consistency of methods).

Acknowledgements. This work is part of the Center for Disaster Management and Risk Reduction Technology (http://www.cedim.de), a joint venture between the Geo-
ForschungsZentrum Potsdam (GFZ) and the Technical University of Karlsruhe (TH). We thank the GFZ Potsdam and the TH Karlsruhe for financial support. The presented hydrologic and hydraulic analyses build on data sets and results from earlier studies at the Institute for Water and River Basin Management (IWG), TH Karlsruhe, which were realized on behalf of the State of Baden-Württemberg. The survey of flood damage data after the 2002 flood was undertaken within the German Research Network Natural Disasters (DFNK), in cooperation between the Section Engineering Hydrology at the GFZ Potsdam and the Deutsche Rückversicherung AG. We thank the Deutsche Rückversicherung AG and the German Ministry for Education and Research (BMBF) (No. 01SFR9969/5) for the financial support. The authors are grateful for all these supports and the fruitful discussions with numerous colleagues in the framework of CEDIM. Furthermore, many thanks to C. Kämpf and K. Dittner, IWG, TH Karlsruhe, for valuable discussions. The paper has benefited significantly from the comments of three referees.

Edited by: A. Thieken

Reviewed by: M. Disse and two other referees

\section{References}

Apel, H., Thieken, A. H., Merz, B., and Blöschl, G.: Flood Risk Assessment and Associated Uncertainty, Nat. Hazards Earth Syst. Sci., 4, 295-308, 2004.

Baden-Württemberg: Hochwassergefahrenkarte BadenWürttemberg, (Flood-hazard map Baden-Württemberg), Umweltministerium Baden-Württemberg, Stuttgart, 2005 (http://www.hochwasser.baden-wuerttemberg.de).

Bayern: Informationsdienst Überschwemmungsgefährdete $\mathrm{Ge}$ biete in Bayern, (Information service flood endangered areas in Bavaria), Bayerisches Landesamt für Wasserwirtschaft, München, 2005 (http://www.geodaten.bayern. de/bayernviewer-aqua/).

BMI (Bundesministerium des Innern): Bundesregierung zieht vorläufige Schadensbilanz der Hochwasserkatastrophe: bisher finanzielle Hilfe im Umfang von über 700 Millionen Euro geleistet (Federal government draws provisional damage balance of the flood disaster: hitherto financial assistance provided to the extent of over 700 million euros), Press release (6 Novem- 
ber 2002, http://www.bmi.bund.de/dokumente/Pressemitteilung/ ix_90912.htm), 2002.

Bobée, B., Cavadias, G., Ashkar, F., Bernier, J., and Rasmussen, P. F.: Towards a systematic approach to comparing distributions used in flood frequency analysis, J. Hydrol., 142, 121-136, 1993.

Buck, W. and Merkel, U.: Auswertung der HOWASSchadendatenbank, (Analysis of the HOWAS data base), Institut für Wasserwirtschaft und Kulturtechnik der Universität Karlsruhe, HY98/15, 1999.

Büchele, B., Kreibich, H., Kron, A., Ihringer, J., Theobald, S., Thieken, A., Merz, B., and Nestmann, F.: Developing a Methodology for Flood Risk Mapping: Examples from Pilot Areas in Germany, in: Disasters and Society - From Hazard Assessment to Risk Reduction, edited by: Malzahn, D. and Plapp, T., LogosVerlag, Berlin, 99-106, 2004.

Cunge, J. A., Holly, F. M., and Verwey, A.: Practical aspects of computational hydraulics, Institute of Hydraulic Research, Iowa, 1980.

Deutsche Rück (Deutsche Rückversicherung AG): Das Pfingsthochwasser im Mai 1999 (The flood at Whitsun in May 1999), Deutsche Rück, Düsseldorf, 1999.

DKKV (Deutsches Komitee für Katastrophenvorsorge e.V.): Hochwasservorsorge in Deutschland - Lernen aus der Katastrophe 2002 im Elbegebiet (Flood risk reduction in Germany - Lessons Learned from the 2002 disaster in the Elbe region), Schriftenreihe des DKKV 29, DKKV, Bonn, 2003.

Dutta, D., Herath, S., and Musiake, K.: A mathematical model for flood loss estimation, J. Hydrol., 277, 24-49, 2003.

DWD: Starkniederschlagshöhen für die Bundesrepublik Deutschland (Heavy precipitation depths for the Federal Republic of Germany), Deutscher Wetterdienst, Offenbach, 1997.

Engel, H.: The flood event 2002 in the Elbe river basin: causes of the flood, its course, statistical assessment and flood damages, Houille Blanche, 2004(6), 33-36, 2004.

FEMA (Federal Emergency Management Agency): Costs and benefits of natural hazard mitigation, Federal Emergency Management Agency, Washington DC, 1998.

Green, C.: Handbook of Water Economics: Principles and Practice, 443 pp., John Wiley and Sons, Chichester, 2003.

Grigg, N. S. and Helweg, O. J.: State-of-the-art of estimating flood damage in urban areas, Water Resour. Bull., 11(2), 379-390, 1975.

Grünthal, G., Thieken, A. H., Schwarz, J., Radtke, K., Smolka, A., Gocht, M., and Merz, B.: Comparative risk assessment for the city of Cologne, Germany - storms, floods, earthquakes, Nat. Hazards, 38(1-2), 21-44, doi:DO00018598, 2006.

Hall, J. W., Dawson, R. J., Sayers, P. B., Rosu, C., Chatterton, J. B., and Deakin, R.: A methodology for national-scale flood risk assessment, Water \& Maritime Engineering, 156, 235-247, 2003.

ICPR (International Commission for the Protection of the Rhine): Rhine-Atlas, ICPR, Koblenz, (http://www.rheinatlas.de), 2001.

ICPR (International Commission for the Protection of the Rhine): Non Structural Flood Plain Management - Measures and their Effectiveness, ICPR, Koblenz, 2002.

Ihringer, J.: Softwarepaket für Hydrologie und Wasserwirtschaft. Anwenderhandbuch. (Software package for hydrology and water resources management. User handbook.), Universität Karlsruhe, 1999.
Ihringer, J.: Ergebnisse von Klimaszenarien und HochwasserStatistik (Results from climate scenarios and flood statistics), Proc. 2nd KLIWA-Symposium, 153-167, Würzburg, (http:// www.kliwa.de), 2004.

IKoNE (Integrierende Konzeption Neckar-Einzugsgebiet): Hochwassermanagement, Partnerschaft für Hochwasserschutz und Hochwasservorsorge (flood management, parnership for flood protection and precaution), Heft 4, Besigheim, 2002.

IKSE (International Commission for the Protection of the Elbe): Dokumentation des Hochwassers vom August 2002 im Einzugsgebiet der Elbe (Documentation of the flood in August 2002 in the Elbe catchment), Magdeburg, 2004.

Kämpf, C., Kron, A., and Ihringer, I.: Design von Simulationswerkzeugen für die Praxis des Hochwassermanagements (design of simulation tools for practice of flood management), Forum für Hydrologie und Wasserbewirtschaftung, Heft 10.05, 157-163, 2005.

Kleeberg, H. B. (Ed.): Hochwasser-Gefahrenkarten (Flood hazard maps), Forum für Hydrologie und Wasserbewirtschaftung, Heft 08.05, 2005.

Kleist, L., Thieken, A., Köhler, P., Müller, M., Seifert, I., and Werner, U.: Estimation of Building Values as a Basis for a Comparative Risk Assessment, in: Disasters and Society - From Hazard Assessment to Risk Reduction, edited by: Malzahn, D. and Plapp, T., Logos-Verlag, Berlin, 115-122, 2004.

Kleist, L., Thieken, A., Köhler, P., Müller, M., Seifert, I., Borst, D., and Werner, U.: Estimation of the regional stock of residential buildings as a basis for comparative risk assessment for Germany, Nat. Hazards Earth Syst. Sci., accepted, 2006.

Kreibich, H., Thieken, A. H., Petrow, T., Müller, M., and Merz, B.: Flood loss reduction of private households due to building precautionary measures - Lessons Learned from the Elbe flood in August 2002, Nat. Hazards Earth Syst. Sci., 5, 117-126, 2005.

Kron, W.: Zunehmende Überschwemmungsschäden: Eine Gefahr für die Versicherungswirtschaft? (Increasing flood damage: a hazard for the insurance industry?), ATV-DVWK: Bundestagung 15-16 September 2004 in Würzburg, DCM, Meckenheim, 4763, 2004.

Krzysztofowicz, R. and Davis, D. R.: Category-unit loss functions for flood forecast-response system evaluation, Water Resour. Res., 19(6), 1476-1480, 1983.

LfU (Landesanstalt für Umweltschutz Baden-Württemberg): Hochwasserabfluss-Wahrscheinlichkeiten in BadenWürttemberg (Flood discharge probabilities in BadenWürttemberg), Oberirdische Gewässer/ Gewässerökologie 54, Karlsruhe, 1999.

LfU (Landesanstalt für Umweltschutz Baden-Württemberg): Hochwasserabfluss-Wahrscheinlichkeiten in BadenWürttemberg - CD (Flood discharge probabilities in BadenWürttemberg - CD), Oberirdische Gewässer/ Gewässerökologie 69, Karlsruhe, 2001.

LfU (Landesanstalt für Umweltschutz Baden-Württemberg): Festlegung des Bemessungshochwassers für Anlagen des technischen Hochwasserschutzes (Definition of the design flood for technical flood protection measures), Oberirdische Gewässer/ Gewässerökologie 92, Karlsruhe, 2005a.

LfU (Landesanstalt für Umweltschutz Baden-Württemberg): Abflusskennwerte in Baden-Württemberg. Teil 1: Hochwasserabflüsse, Teil 2: Mittlere Abflüsse und Mittlere Niedrigwasser- 
abflüsse (Flow parameters in Baden-Württemberg: Part 1: Flood discharges, Part 2: Mean flows and low flows), Oberirdische Gewässer/ Gewässerökologie 94, Karlsruhe, 2005b.

Lutz, W.: Berechnung von Hochwasserabflüssen unter Anwendung von Gebietskenngrößen (Calculation of flood discharges with application of spatial parameters), Mitteilungen des Instituts für Hydrologie und Wasserwirtschaft, Universität Karlsruhe, Heft 24, 1984.

McBean, E. A., Gorrie, J., Fortin, M., Ding, J., and Moulton, R.: Adjustment Factors for Flood Damage Curves, J. Water Res. Plan. Man., 114(6), 635-645, 1988.

Merz, B. and Thieken, A. H.: Flood risk analysis: Concepts and challenges, Österreichische Wasser- und Abfallwirtschaft, 56(34), 27-34, 2004.

Merz, B, Kreibich, H., Thieken, A. H., and Schmidtke, R.: Estimation uncertainty of direct monetary flood damage to buildings, Nat. Hazards Earth Syst. Sci., 4, 153-163, 2004.

Merz, B. and Thieken, A. H.: Separating Aleatory and Epistemic Uncertainty in Flood Frequency Analysis, J. Hydrol., 309, 114132, 2005.

Mileti, D. S.: Disasters by design. A reassessment of natural hazards in the United States, Joseph Henry Press, Washington D.C., 1999.

MUNLV (Ministerium für Umwelt und Naturschutz, Landwirtschaft und Verbraucherschutz des Landes NordrheinWestfalen): Leitfaden Hochwasser-Gefahrenkarten (Guideline flood-hazard maps), Düsseldorf, 2003.

MURL (Ministerium für Umwelt, Raumordnung und Landwirtschaft des Landes Nordrhein-Westfalen): Potentielle Hochwasserschäden am Rhein in NRW (Potential flood damage at the Rhine in North-Rhine Westfalia), Düsseldorf, 2000.

Nordrhein-Westfalen: Hochwassergefährdete Bereiche (Flood endangered areas). Landesumweltamt Nordrhein-Westfalen, Düsseldorf, (http://www.lua.nrw.de/index.htm?wasser/hwber. htm), 2003.

NRC (National Research Council): Risk analysis and uncertainty in flood damage reduction studies. National Academy Press, Washington D.C., 2000.

Oberle, P., Theobald, S., and Nestmann, F.: GIS-gestützte Hochwassermodellierung am Beispiel des Neckars (GIS-based flood simulation exemplified for the Neckar River), Wasserwirtschaft, 90(7-8), 368-373, 2000.

Oberle, P.: Integrales Hochwassersimulationssystem Neckar Verfahren, Werkzeuge, Anwendungen und Übertragung (Integral flood simulation system Neckar - methods, tools, applications and transfer), Mitteilungen des Instituts für Wasser und Gewässerentwicklung, Heft 226, 2004.

Parker, D. J., Green, C. H., and Thompson, P. M.: Urban Flood Protection Benefits: A project appraisal guide. Gower Technical Press, Aldershot, 1987.

Penning-Rowsell, E. C. and Chatterton, J. B.: The Benefits of Flood Alleviation: A Manual of Assessment techniques. Gower Technical Press, Aldershot, 1977.

Penning-Rowsell, E. C. and Green, C.: New Insights into the appraisal of flood-alleviation benefits: (1) Flood damage and flood loss information, J. Chart. Inst. Water E., 14, 347-353, 2000.

Penning-Rowsell, E. C., Fordham, M., Correia, F. N., Gardiner, J., Green, C., Hubert, G., Ketteridge, A.-M., Klaus, J., Parker, D., Peerbolte, B., Pflügner, W., Reitano, B., Rocha, J., Sanchez-
Arcilla, A., Saraiva, M. d. G., Schmidtke, R., Torterotot, J.-P., van der Veen, A., Wierstra, E., and Wind, H.: Flood hazard assessment, modelling and management: Results from the EUROflood project, in: Floods across Europe: Flood hazard assessment, modelling and management, edited by: Penning-Rowsell, E. C. and Fordham, M., 37-72, Middlesex University Press, London, 1994.

Rheinland-Pfalz: Grenzüberschreitender Atlas der Überschwemmungsgebiete im Einzugsgebiet der Mosel (Transboundary atlas of the inundation areas in the basin of the river Mosel), Struktur- und Genehmigungsdirektion Nord, Regionalstelle für Wasserwirtschaft, Abfallwirtschaft, Bodenschutz Trier, (http:// www.gefahrenatlas-mosel.de), 2004.

Sachsen: Gefahrenhinweiskarte Sachsen (Hazard information map Saxony), Sächsisches Landesamt für Umwelt und Geologie, Dresden, (http://www.umwelt.sachsen.de/de/wu/umwelt/ lfug/lfug-internet/interaktive_karten_10950.html) 2004.

Smith, D. I.: Actual and potential flood damage: a case study for urban Lismore, NSW, Australia. Appl. Geography, 1, 31-39, 1981.

Smith, D. I.: Flood damage estimation - A review of urban stagedamage curves and loss functions, Water SA, 20(3), 231-238, 1994.

Smith, K. and Ward, R.: Floods - Physical processes and Human Impacts, Chichester: Wiley, 1998.

Soetanto, R. and Proverbs, D. G.: Impact of flood characteristics on damage caused to UK domestic properties: The perceptions of building surveyors, Struct. Surv., 22(2), 95-104, 2004.

SSK (Sächsische Staatskanzlei): Augusthochwasser 2002 - Der Wiederaufbau in Sachsen ein Jahr nach der Flut (Flood event August 2002 - the reconstruction in Saxony one year after the flood), Dresden, 2003.

Takeuchi, K.: Increasing vulnerability to extreme floods and societal needs of hydrological forecasting, Hydrol. Sci. J., 46(6), 869-881, 2001.

Thieken, A. H., Müller, M., Kreibich, H., and Merz, B.: Flood damage and influencing factors: New insights from the August 2002 flood in Germany, Water Resour. Res., 41(12), W12430, doi:101029/2005WR004177, 2005.

Uhrich, S., Krause, J., Bormann H., and Diekkrüber, B.: Simulation von Überflutungen bei Hochwasserereignissen: Risikoeinschätzung und Unsicherheiten (Simulation of inundations due to flood events: risk assessment and uncertainties), in: Tagungsbericht 5. Workshop zur hydrologischen Modellierung: Möglichkeiten und Grenzen für den Einsatz hydrologischer Modelle in Politik, Wirtschaft und Klimafolgeforschung, edited by: Stephan, K., Bormann, H., and Diekkrüger, B., Kassel University Press, Kassel, 59-70, 2002.

UM Baden-Württemberg (Umweltministerium BadenWürttemberg): Hochwassergefahrenkarten Baden-Württemberg, Leitfaden (Flood-hazard maps Baden-Württemberg, guideline), Stuttgart, 2005.

USACE (U.S. Army Corps of Engineers): Risk-based analysis for flood damage reduction studies, Engineering Manual 1110-21619, Washington D.C., 1996.

Wind, H. G., Nieron, T. M., de Blois, C. J., and de Kok, J. L.: Analysis of flood damages from the 1993 and 1995 Meuse floods, Water Resour. Res., 35(11), 3459-3465, 1999. 